\title{
Changes in hydro-meteorological conditions over tropical West Africa $(1980-2015)$ and links to global climate
}

\author{
Christopher E. Ndehedehe ${ }^{\mathrm{a}, \mathrm{b}, *}$, Joseph L. Awange ${ }^{\mathrm{a}}$, Nathan O. Agutu ${ }^{\mathrm{a}, \mathrm{c}}$, Onuwa Okwuashi ${ }^{\mathrm{b}}$ \\ ${ }^{a}$ School of Earth and Planetary Sciences, Spatial Sciences, Curtin University, Perth, Western Australia, \\ Australia. \\ ${ }^{b}$ Department of Geoinformatics and Surveying, University of Uyo, P.M.B. 1017, Uyo, Nigeria. \\ ${ }^{c}$ Department of Geomatic Engineering and Geospatial Information Systems JKUAT, Nairobi, Kenya.
}

\section{Abstract}

The role of global sea surface temperature (SST) anomalies in modulating rainfall in the African region has been widely studied and is now less debated. However, their impacts and links to terrestrial water storage (TWS) in general, have not been studied. This study presents the pioneer results of canonical correlation analysis (CCA) of TWS derived from both global reanalysis data (1980-2015) and GRACE (Gravity Recovery and Climate Experiment) (2002 - 2014) with SST fields. The main issues discussed include, (i) oceanic hot spots that impact on TWS over tropical West Africa (TWA) based on CCA, (ii) long term changes in model and global reanalysis data (soil moisture, TWS, and groundwater) and the influence of climate variability on these hydrological indicators, and (iii) the hydrological characteristics of the Equatorial region of Africa (i.e., the Congo basin) based on GRACE-derived TWS, river discharge, and precipitation. Results of the CCA diagnostics show that El-Niño Southern Oscillation related equatorial Pacific SST fluctuations is a major index of climate variability identified in the main portion of the CCA procedure that indicates a significant association with long term TWS reanalysis data over TWA $(r=0.50, \rho<0.05)$. Based on ManKendall's statistics, the study found fairly large long term declines $(\rho<0.05)$ in TWS and soil moisture $(1982-2015)$, mostly over the Congo basin, which coincided with warming of the land surface and the surrounding oceans. Meanwhile, some parts of the Sahel show significant wetting (rainfall, soil moisture, groundwater, and TWS) trends during the same period (1982 - 2015) and aligns with the ongoing narratives of rainfall recovery in the region. Results of singular spectral analysis and regression confirm that multi-annual changes in the Congo river discharge explained a considerable proportion of variability in GRACEhydrological signal over the Congo basin $\left(r=0.86\right.$ and $\left.R^{2}=0.70, \rho<0.05\right)$. Finally, leading orthogonal modes of MERRA and GRACE-TWS over TWA show significant association with global SST anomalies.

Keywords: Rainfall, land water storage, canonical correlation analysis, ENSO, Congo basin, climate variability 


\section{Introduction}

Global interest in climate change is growing because of its anticipated impacts on agriculture, water security, and economic growth. As projected, impacts of climate change is expected to have direct and profound negative effects on freshwater availability (see, e.g., Tall et al., 2016; Prudhomme et al., 2014; Schewe et al., 2013). As a result, the focus on changes in hydro-meteorological conditions and water resources is receiving increasing attention (e.g., Andam-Akorful et al., 2017; Ndehedehe et al., 2016a; Hall et al., 2014; Shiferaw et al., 2014; Zhang et al., 2009; Conway et al., 2009; Descroix et al., 2009; Bekoe and Logah, 2013), especially with the perceived risk and vulnerability of future losses and socio-economic problems (e.g., migration, famine, etc.) resulting from the acceleration of the water cycle.

Extreme hydro-meteorological conditions and strong hydrological variability are unpredictable outcomes of changes in global climate that impacts on socio-economic systems of the world. In Thailand, for example, about 59 billion dollars was lost to the 2011 flood while economic growth was down by $38 \%$ due to hydrological variability in Ethiopia (see, Hall et al., 2014). Whereas the productive seasons of the year are restricted in monsoonal and tropical climates of the world due to strong seasonal and inter-annual rainfall variability (see, Hall et al., 2014), the preponderance of evidence from considerable case studies in the African sub-region (see, e.g., Ndehedehe et al., 2016b; Nicholson, 2013; Mohino et al., 2011a; Bader and Latif, 2011; Losada et al., 2010; Giannini et al., 2008; Todd and Washington, 2004; Nicholson et al., 2000) confirm that atmospheric circulation features, warming of the tropical oceans, mesoscale convective systems, and climate teleconnections, amongst others have large impacts on meteorological processes and induce extreme climatic conditions. Such impacts, teeming up with other low-frequency variability that are connected to slow oceanic and climate signals from global sea surface temperature (SST) anomaly (e.g., Diaz et al., 2001; Enfield and Mestas-Nuñez, 1999; Latif and Barnett, 1996), may have profound influence on hydrological changes and water resources.

Studies of changes in global climate and how they impact on meteorological and hydrological processes, are without doubt, emerging as active research. So far, our understanding of global climate has improved due to significant progress and advances made in global and regional climate models (i.e., GCMs and RCMs) (see, e.g., Tall et al., 2016; Erfanian et al., 2016; Prudhomme et al., 2014; Dimri et al., 2013; Schewe et al., 2013; Mishra et al., 2012; Li et al., 2004; Lebel et al., 2000). However, in regions where strong hydrological variability have been linked to multiple environmental phenomena such as large scale ocean-atmosphere phenomenon (e.g., Joly and Voldoire, 2010; Redelsperger and Lebel, 2009), land use changes (e.g., Favreau et al., 2009; Descroix et al., 2009), and other human interventions (e.g., surface water schemes) (e.g., Ngom et al., 2016; Ndehedehe et al., 2017a; Ahmed et al., 2014), the skills of climate and hydrological models may be restricted. Primarily, this maybe due to a 
number of factors that include, e.g., model dependence on computational estimates, model physics, choice of parameterisations, bias, conceptual model and parameter uncertainties (e.g., Oettli et al., 2011; Schuol and Abbaspour, 2006; Koster et al., 2004; Lebel et al., 2000). Despite their potential useful applications in optimisation of water allocation schemes, early warning systems, and estimation of water availability (e.g., Thiemig et al., 2013), the restrictions of outputs from hydrological models, may affect meaningful management decisions related to water resources.

The failure of GCMs to produce a realistic climatology in West Africa, for example, can be damaging to hydrological applications (see, Lebel et al., 2000). All of the aforementioned issues represent significant setbacks that have contributed to the poor understanding of hydrological variability (e.g., Hall et al., 2014), especially in Africa, a region characterised by strong inter-annual variability. The lack of sufficient in-situ and direct observations of land surface data (e.g., Alsdorf and Lettenmaier, 2003; Lettenmaier, 2005; Robock et al., 2000) generally affects regional configurations and adequate initialization of models (e.g., Jenkins et al., 2002) for the purposes of hydrological studies. This problem can only be more intense in non-industrialised regions such as tropical West Africa (TWA) (Fig. 1), where in-situ observations are either considerably sparse or unavailable (see, Conway et al., 2009) due to lack of robust investments in gauge measurements. Hence, more research using auxiliary data synthesized by forcing global land surface models with historical meteorological data (e.g., Paolino et al., 2012; Sheffield and Wood, 2008), are required to further assess the representation of the land surface and atmospheric states in global reanalysis models.

TWA is indeed a strong climatic hot spot that play key roles in global climate. For instance, the Congo basin's rainfall climatology dominates global tropical rainfall during transition seasons (see, Washington et al., 2013). The long term decline in vegetation greenness in the Central African rainforests, the second-largest on Earth (Zhou et al., 2014), are indications that global biodiversity are under significant threat due to climatic disturbance. Sheffield and Wood (2008) found large increase in drought extent over West Africa compared to other global terrestrial areas. Furthermore, observed trends in the magnitude and frequency of flood events in the Sahel and Sudano regions (Nka et al., 2015), strong water deficit anomalies in West and Central Africa during the 2005 - 2007 period (see, Ndehedehe et al., 2016a; Asefi-Najafabady and Saatchi, 2013), and the recent long term drying of Central African Republic (e.g., Hua et al., 2016), are without doubt coherent impacts of climate variability and indicators of climate change in the region. Although it is now less debated that the global SST anomalies regulate rainfall in TWA (see, e.g., Odekunle and Eludoyin, 2008; Nicholson and Webster, 2007; Fontaine and Bigot, 1993; Semazzi et al., 1988; Nicholson, 2013, and the references therein), their impacts on and links to TWS and water fluxes (e.g., river discharge), in general, have not been studied. As with rainfall, the annual am- 
plitudes and leading modes of land water storage (terrestrial water storage-TWS) and river discharge in TWA are presumably expected to be influenced by ENSO-related Pacific SST fluctuations and other triggers of ENSO, for example, SST anomalies of the north tropical Atlantic (see, e.g., Ham et al., 2013). Identifying the association between TWS and SST therefore requires consideration, and is significant to understanding global aspects of ENSO effects, for example, on regional hydrology.

As opposed to all of these aforementioned studies and those highlighted earlier, this study presents the pioneer results of canonical correlation analysis (CCA, e.g., Barnett and Preisendorfer, 1987; Graham et al., 1987; Glahn, 1968) of TWS derived from both reanalysis data and GRACE (Gravity Recovery and Climate Experiment) with global SST fields over TWA. The novel and underlying issues discussed include, (i) the linking of homogenous regions of TWS amplitudes to specific zones of global SSTs based on CCA, (ii) analysing the long term changes in water fluxes and state variables (rainfall, river discharge, soil moisture, TWS, and groundwater), and (iii) examining the hydrological properties of the Equatorial region of Africa (i.e., the Congo basin), which is prominently under-represented in hydrological research compared to other key global basins (see, Alsdorf et al., 2016). Since the global climate is also affected by tropospherically connected ENSO signals in other global oceans (see, e.g., Enfield and Mestas-Nuñez, 1999; Latif and Barnett, 1996), the link between long term changes in land water storage of the region and SST anomalies of the Pacific, Indian, and Atlantic Oceans requires reckoning. This is essential to (i) enhance the skills of hydrological models, (ii) close the gap of poorly understood complex regional hydrology and water fluxes, and (iii) examine the potential indices of climate variability that are associated with hydrological changes in TWA.

The three main objectives of this study are (i) to examine long term trends in water fluxes $(1980-2015)$ and the influence of climate variability on long term changes in these water fluxes over TWA, (ii) to examine oceanic hot spots that impacts on TWS over TWA based on CCA, and (iii) to assess the hydrological characteristics of the Congo basin based on GRACE observations, river discharge, and precipitation.

\section{Data}

The data used in this study have been summarised in Table 1.

\subsection{Terrestrial water storage (TWS)}

(1) Modern-Era Retrospective Analysis for Research and Applications (MERRA) National Aeronautic and Space Administration (NASA) global high-resolution MERRA reanalysis data (see, Rienecker et al., 2011) was used to analyse the long term TWS and soil moisture trends. The data is a state-of-the-art reanalysis that provides atmospheric fields, water fluxes, and global estimates of soil moisture (e.g., Rienecker 


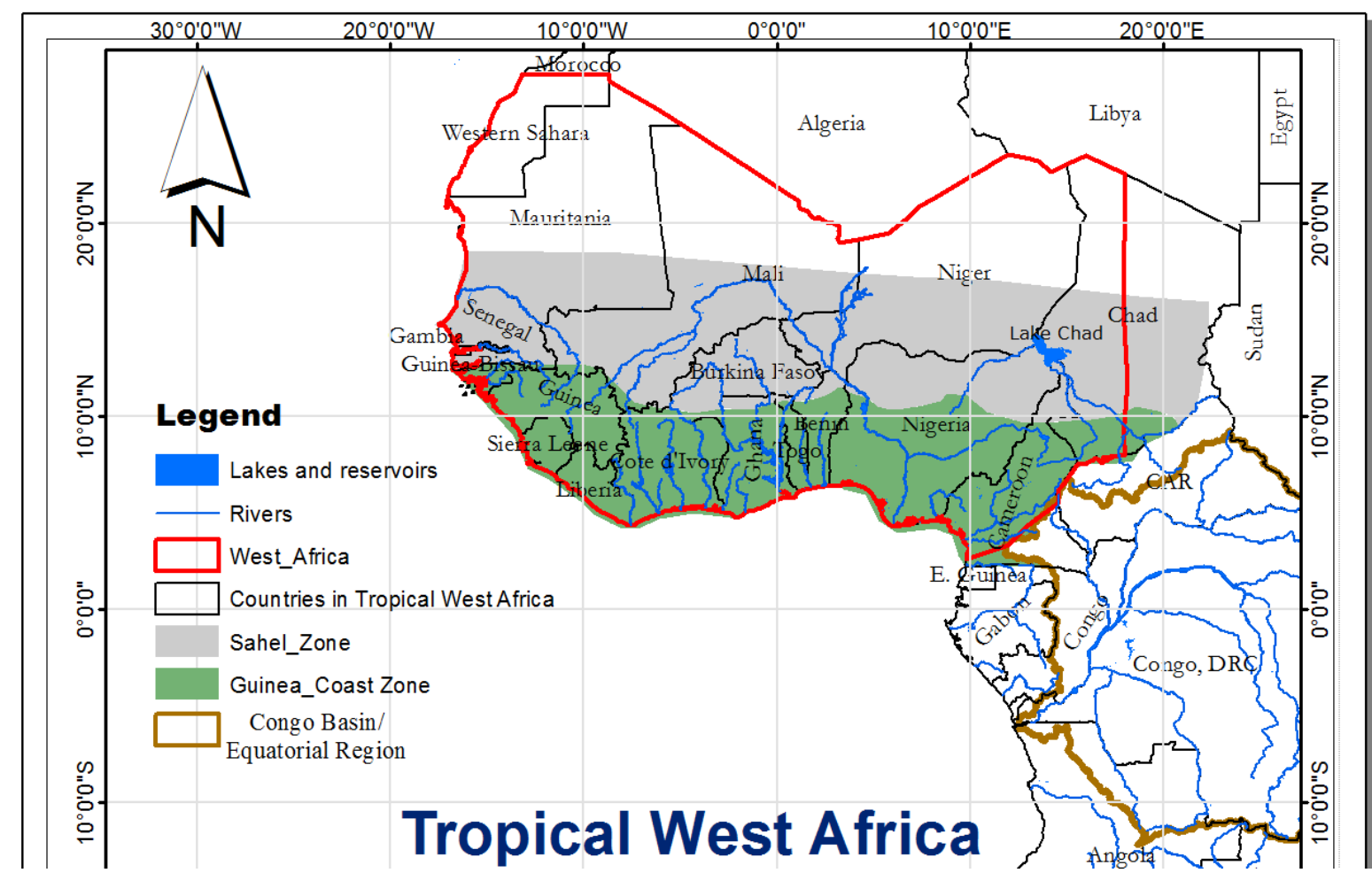

Figure 1: Study area showing some countries in tropical West Africa (TWA) and environ. Other major hydrological sub-regions (i.e., Sahel, Guinea Coast (used interchangeably as coastal West Africa in the manuscript), West Africa, Congo basin/Equatorial countries) in TWA have also been indicated. The freshwater resources (lakes, rivers, and reservoirs) of the region are also shown.

et al., 2011; Reichle et al., 2011). Also, it has been improved significantly compared to previous reanalysis datasets (Rienecker et al., 2011). MERRA outputs have been used in the study of atmospheric circulations, agricultural drought assessment, and climate teleconnections in the African continent (e.g., Wu et al., 2013; Agutu et al., 2017; Ndehedehe et al., 2017b) and has been recommended for land surface hydrological studies (see, Reichle et al., 2011). The land TWS data component of MERRA used in this study, covers the period of $1980-2015$ and is available for download through NASA's website (http://disc.sci.gsfc.nasa.gov/mdisc/). The MERRA TWS (which are in kg $m^{-2}$ similar to millimeters-mm) was employed to highlight the influence of climate variability on long term terrestrial stored water over TWA, complementing the limited GRACE-TWS data record.

(2) WaterGap Global Hydrology Model (WGHM)

A new version of the global hydrological model (WaterGAP 2.2a) (see, Döll et al., 2014a) was used to derive TWS and groundwater component over TWA. This model takes into account groundwater recharge from surface water bodies in semi arid and arid regions and groundwater depletion. The WaterGAP model data covering the period $1980-2009$ with a spatial resolution of $1^{\circ} \times 1^{\circ}$ was downloaded from Center 
for Environment Systems Research (CESR).

\section{(3) Gravity Recovery and Climate Experiment (GRACE)} GRACE (Tapley et al., 2004) monthly Release-05 (RL05) spherical harmonic coefficients (degree and order 60 from Center for Space Research-CSR) (data files available at http://icgem.gfz-potsdam.de/ICGEM/shms/monthly/csr-rl05/), covering the period 2002 - 2014 were processed following the approach of Wahr et al. (1998) as detailed in previous studies (see, e.g., Ndehedehe et al., 2016a; Landerer and Swenson, 2012). The suitability of TWS outputs from reanalysis and model outputs were assessed by comparing with GRACE-derived TWS using Pearson correlation. Since GRACE observations provide an overall picture of the water budget, the principal driver of its variability over the Congo basin was investigated using both rainfall data (Section 2.2) and the river discharge from the Congo Kinshasa station (Section 2.4). Their links to SST anomalies, on the other hand were examined to understand the vulnerability of the region's stored water to climate variability.

\subsection{Precipitation data}

\section{Global Precipitation Climatology Centre (GPCC)}

GPCC (Schneider et al., 2014) provides reliable monthly gridded data sets of global land-surface precipitation, covering the period from 1901 to present. The $1.0^{\circ} \times 1.0^{\circ}$ GPCC data was downloaded from the GPCC open access portal (www.ftp.dwd.de/pub /data/gpcc/html/downloadgate.html) and used in the study to analyse the spatial and temporal patterns of rainfall in the region during the $1980-2014$ period.

2. Climate Hazards group Infrared Precipitation with Stations (CHIRPS)

Monthly CHIRPS (see, Funk et al., 2015) precipitation data $(1981-2015)$ with a spatial resolution of $0.05^{\circ} \times 0.05^{\circ}$ was also used in this study. The CHIRPS (data available at ftp://ftp.chg.ucsb.edu/pub/org/chg/products/CHIRPS-2.0/) algorithm incorporates gauged locations and infrared Cold Cloud Duration (CCD) precipitation estimates. Its validation results at global and regional scales show that it is useful for hydrological studies of regions (e.g., Ethiopia) with complex topography, and deep convective precipitation systems. To explore the potential of monthly higher spatial $\left(0.05^{\circ}\right.$ $\mathrm{x} 0.05^{\circ}$ ) resolution of the data, it was employed to study long term spatial and temporal dynamics of rainfall over TWA.

\subsection{Soil moisture data}

1. Climate Prediction Center (CPC) Soil Moisture

Soil moisture analysis is important in studies of land surface hydrological processes and drought/flood monitoring applications (see, Fan and Dool, 2004). Monthly CPC 
soil moisture data (Fan and Dool, 2004) with spatial resolution of $0.5^{\circ} \times 0.5^{\circ}$ for the period between 1980 to 2014 was used in this study to investigate long term changes in soil moisture. Though a one layer water balance model, the CPC soil moisture product is derived from monthly global rainfall data that uses more than 17000 rain gauges worldwide and monthly global temperature from reanalysis. The data is freely available at National Oceanic \& Atmospheric Administration (NOAA, http://www.esrl.noaa.gov/psd/data/gr idded/data.cpcsoil.html) for download.

\section{MERRA Soil Moisture}

The understanding of extreme hydro-meteorological conditions (e.g., drought) and the climate system rely on the knowledge of soil moisture changes (Robock et al., 2000). Hence, the soil moisture outputs of the MERRA product was also used in this study to analyse the long term trends and spatio-temporal variability in soil moisture over TWA. The data is in volumetric units $\left(\mathrm{m}^{3} \mathrm{~m}^{-3}\right)$ and covers the period between 1980 and 2015 .

\subsection{Global Runoff Data Centre (GRDC)-river discharge data}

GRDC (www.bafg.de/GRDC) provides river discharge data of nearly 9000 gauging stations from all over the world. In this study, river discharge data from 1980 - 2010 (see Table 1) at Congo Kinshasa station was used to analyse hydrological conditions over the Congo basin.

\subsection{Sea Surface Temperature (SST)}

SST (Reynolds et al., 2002) data (i.e., Atlantic, Indian, and Pacific Oceans) was downloaded from NOAA's official earth system research laboratory portal (http://www.esrl.noaa.gov/psd/d ata/gridded/data.noaa.oisst.v2.html) for the period covering 1982 to 2014 and used to investigate the impacts of large scale ocean-atmosphere interactions on TWS over TWA.

\subsection{Global Land Data Assimilation System (GLDAS)}

The land surface temperature used in this study was derived from the CLM component of GLDAS. The data (Table 1) covering the years 1982-2014 was obtained from the Goddard Earth Sciences Data and Information Services Center (GESDICS) (http://grace.jpl.nasa.gov/d ata/gldas/).

\section{Method}

\subsection{Canonical correlation analysis}

The canonical correlation analyses (CCA, see, Graham et al., 1987; Glahn, 1968; Hotelling, 1936), a multivariate statistical method that determines a linear combination of two different 
Table 1: Summary of precipitation, soil moisture, TWS, and other hydrological data used in this study.

\begin{tabular}{|c|c|c|c|c|c|c|}
\hline Data & Type & Period & Spatial Res. & Temporal Res. & Coverage & References \\
\hline \multicolumn{7}{|c|}{ Precipitation products } \\
\hline GPCC & Guage & $1901-2014$ & $1.0^{\circ} \times 1.0^{\circ}$ & Monthly & Global & Schneider et al. (2014) \\
\hline CHIRPS & Satellite \& gauge & $1981-2015$ & $0.05^{\circ} \times 0.05^{\circ}$ & Monthly & Global & Funk et al. (2015) \\
\hline \multicolumn{7}{|c|}{ Soil moisture products } \\
\hline $\mathrm{CPC}$ & Model & $1948-2014$ & $0.5^{\circ} \times 0.5^{\circ}$ & Monthly & Global & Fan and Dool (2004) \\
\hline MERRA & Reanalysis & $1980-2015$ & $0.625^{\circ} \times 0.5^{\circ}$ & Monthly & Global & Rienecker et al. (2011) \\
\hline \multicolumn{7}{|c|}{ Terrestrial water storage products } \\
\hline WGHM & Model & $1980-2009$ & $1.0^{\circ} \times 1.0^{\circ}$ & Monthly & Global & Döll et al. (2014b) \\
\hline MERRA & Reanalysis & $1980-2015$ & $0.625^{\circ} \times 0.5^{\circ}$ & Monthly & Global & Rienecker et al. (2011) \\
\hline GRACE & Satellite & $2002-2014$ & $1.0^{\circ} \times 1.0^{\circ}$ & Monthly & Global & Tapley et al. (2004) \\
\hline \multicolumn{7}{|c|}{ Others } \\
\hline GLDAS & Model & $1982-2014$ & $1.0^{\circ} \times 1.0^{\circ}$ & Monthly & Global & Rodell et al. (2004) \\
\hline SST & Satellite & $1982-2014$ & $1.0^{\circ} \times 1.0^{\circ}$ & Monthly & Global & Reynolds et al. (2002) \\
\hline GRDC & Gauge & $1980-2010$ & & Monthly & Congo & (www.bafg.de/GRDC) \\
\hline
\end{tabular}

sets of variables such that the correlation between the two functions is a maximum, was employed in this study. Specifically, it was employed to examine the interrelationship between the leading modes of SST and inter-annual variations of TWS. Although the CCA technique bears some similarity to principal component analysis (PCA, e.g., Jolliffe, 2002; Preisendorfer, 1988) and multiple linear regression, it is usually viewed as a 'double-barreled' PCA (e.g., Wilks, 2011; Graham et al., 1987; Glahn, 1968), emphasizing its robustness over similar methods. Before applying the CCA technique, the SST (predictor) over the three oceans (Atlantic, Indian and Pacific) and TWS (predictand) were pre-orthogonalized and regularized (pre-filtering of the original data) using the PCA technique. This is a standard procedure when applying CCA on climate data (see, e.g., Singh et al., 2012a; Repelli and Nobre, 2004; Yu et al., 1997; Shabbar and Barnston, 1996), mostly because the large spatial fields causes difficulty in inverting the matrices and in the eigenvalue problem, leading to instabilities in the CCA solution. Because the CCA is a form of least squares regression, it is vulnerable to all the potential problems associated with matrix inversion inherent in least squares method (see, Graham et al., 1987). The pre-filtering of the original data addresses these problems, which includes artificial skills and the uncertainties introduced by correlated predictors (see, Graham et al., 1987), by reducing the number of orthogonal predictors analysed in the primary portion of the CCA procedure.

The pre-orthogonalization process allowed an initial comparison of the dominant modes (the first and second modes were selected for the regression because of their physical interpretability) of the predictor with the predictand based on regression. The CCA procedure was made up of four dominant modes of TWS (GRACE and MERRA) variability and three modes of SST variability over the three Oceans (Atlantic, Indian, and Pacific). Consider that two matrices, $\mathbf{X}_{p, t}$ and $\mathbf{Y}_{q, t}$ represent the predictor (SST) and the predictand (TWS), 
respectively, where $p$ and $q$ are the spatial points (observations) and $t$ represents the time (months) for each observation. After removing the mean of $\mathbf{X}_{p, t}$ and $\mathbf{Y}_{q, t}$, their statistical decomposition using the PCA technique results in

$$
\mathbf{X}_{p, t}=B_{p, p} T_{p, t}
$$

$$
\mathbf{Y}_{q, t}=B_{q, q} T_{q, t}
$$

where $B_{p, p}$ and $B_{q, q}$ are the empirical orthogonal functions-EOFs (spatial patterns or the EOF loadings) of the predictor and predictand matrices, respectively, and $T_{p, t}$ and $T_{q, t}$ represents their corresponding time coefficients (see, e.g., Singh et al., 2012b; Yu et al., 1997; Graham et al., 1987). Assuming that $i, j$ are the retained PCA modes of the predictor and predictand time series, the canonical variables $(u$ and $v$ ) and the linear combinations of

$$
Z=u^{\prime} T_{i, t} \text { and } W=v^{\prime} T_{j, t},
$$

can be determined using these retained modes as inputs to the CCA. The objective of CCA is to calculate two new paired sets of variables,

$$
\mathbf{U}=\left[u^{\prime}, u_{2}^{\prime} \ldots, u_{n}^{\prime}\right]^{\prime}
$$

$$
\mathbf{V}=\left[v^{\prime}, v_{2}^{\prime} \ldots, v_{n}^{\prime}\right]^{\prime},
$$

that are linear combinations of $\mathbf{X}$ and $\mathbf{Y}$, respectively. The CCA is solved under the condition that $u$ and $v$ are maximally correlated (see, Yu et al., 1997; Graham et al., 1987; Glahn, 1968). The correlation $\mathrm{C}$ is given as

$$
\mathbf{C}_{n, n}=\left[\begin{array}{llll}
c_{1} & & & 0 \\
& c_{2} & & \\
& & \cdot & \\
0 & & & c_{n}
\end{array}\right],
$$

where $c_{1}, \ldots, c_{n}$ are the canonical correlations between $\mathrm{Z}$ and $\mathrm{W}$, and $c_{1} \geq c_{2} \geq \ldots ., \geq c_{n}$ and $n$ are equivalent to $i$ or $j$, depending on which is smaller. The reconstructed fields of the predictor and predictands from the PCA procedure (i.e., their EOFs) are projected into the temporal series $(u$ and $v$ ) or canonical components to generate their corresponding spatial maps (i.e., for the predictands and predictors). These spatial maps are referred to as $g-$ map (predictor map) and $h-$ map (predictand map) and are used to investigate the regions of variability in the the predictor fields that impacts on the variability of the predictand fields (see, Repelli and Nobre, 2004).

Compared to other prominent statistical tools (e.g., multiple regression and PCA), the CCA method is not very popular probably owing to its complex methodology. However, the method is robust and very useful in empirical climate forecast and diagnosing aspects of the 
coupled effect between oceans warming and meteorological patterns (see, e.g., Singh et al., 2012a; Repelli and Nobre, 2004; Yu et al., 1997; Shabbar and Barnston, 1996; Graham et al., 1987). Since CCA seeks to identify new sets of variables that optimizes the relationships between two data sets contrary to the PCA technique (e.g., Wilks, 2011), it was employed to investigate the indices of climate variability that impacts on TWS through a diagnostic of the interrelationships between global SST and inter-annual variations of TWS. It is worth noting that the spatio-temporal characteristics of long term changes in rainfall, soil moisture, and TWS over TWA during the 1980 - 2015 period were also studied using the PCA method indicated in Eqns. 1 and 2. Apart from the more compact representation of variabilities in multivariate data, the PCA technique is an important tool for exploring large multivariate data (e.g., Jolliffe, 2002; Wilks, 2011). Studying the long term spatial and temporal dynamics of these fluxes over TWA, where several mechanisms drive the climate system requires a multivariate statistics such as the PCA technique. PCA has the potential for yielding substantial insights into the spatial and temporal dynamics exhibited by these fluxes. The method has gained prominence in climate science and has been widely applied in meteorological (see, e.g., Sanogo et al., 2015; Fontaine and Bigot, 1993; Janicot, 1992; Janowiak, 1988; Semazzi et al., 1988) and hydrological (see, Ndehedehe et al., 2016a; Rangelova et al., 2007) studies.

\subsection{Singular spectral analysis}

Singular spectrum analysis (see, e.g., Ghil et al., 2002, and the references therein) was employed to analyse monthly river discharge $(2002-2010)$ through a singular value decomposition (SVD) of the lagged covariance matrices. The method embeds a time series $\left\{X_{\text {discharge }}(t): t=1, \ldots, N\right\}$ in a vector space of dimension $M$. The embedding approach constructs a sequence of $\left\{\mathbf{X}_{\text {discharge }}(t)\right\}$ of $M$-dimensional vectors from the original time series by using lagged copies of the scalar data $\left\{X_{\text {discharge }}(t): 1 \leq t \leq N\right\}$ (see, Ghil et al., 2002),

$$
\mathbf{X}_{\text {discharge }}(t)=(X(t), X(t+1, \ldots, X(t+M-1)),
$$

the vectors $\mathbf{X}_{\text {discharge }}(t)$ are indexed by $t=1, \ldots, N^{\prime}$, where $N^{\prime}=N-M+1$. The singular spectral analysis calculates the principal directions of extension of the sequence of augmented vector $\left\{\mathbf{X}_{\text {discharge }}(t): t=1, \ldots, N^{\prime}\right\}$ in phase space using an eigenvalue-eigenvector decomposition of the $M \times M$ covariance matrix or simply through a SVD of the trajectory matrix (see more details in Ghil et al., 2002). From the SVD decomposition, meaningful time series are reconstructed by means of diagonal averaging (see, e.g., Unnikrishnan and Jothiprakash, 2015; Ghil et al., 2002). The method offers useful insights into understanding non-linear systems and is here employed to explore the relationship of river discharge oscillations of the Congo basin with GRACE-derived TWS. 


\subsection{Trends and annual amplitudes}

The annual amplitudes of all fluxes (except river discharge) were estimated using the Multiple Linear Regression Analysis (MLRA). The harmonic components (e.g., annual, semi annual, etc.) of each data were formulated as detailed in Ndehedehe et al. (2016a). Furthermore, using a non-parametric method, trends in rainfall, soil moisture, groundwater and TWS were estimated for each grid cell. Based on the least squares estimation of the regression coefficient, MLRA can also be used to estimate trends as parameterised in Ndehedehe et al. (2016a). However, the Sen's slope (Sen, 1968) estimator was used to estimate trends since it is robust and resistant to outliers. Sen slope $\left(S_{i}\right)$ is the median overall values of the whole data and is estimated as

$$
S_{k}=\operatorname{Median}\left(\frac{P_{j}-P_{i}}{j-i}\right), \text { for }(1 \leq i<j \leq n),
$$

where $P_{j}$ and $P_{i}$ represents data values at time $j$ and $i(j>i)$, respectively while $n$ is the number of data. The slope can be positive indicating increasing trend or negative, indicating decreasing trend. The significance of observed trends was tested using the Man-Kendall's test (Mann, 1945; Kendall, 1970), a widely used non-parametric method in testing the significance of trends. Parametric trend tests (e.g., Student $t$ test, turning point, regression, inversion tests, etc.) can also be used to examine the statistical significance of trends but sometimes they violate normality, hence the popularity and preference of non-parametric methods such as the Man-Kendall, Hotelling-Pabst test, and Sen test amongst others (see, Machiwal and Jha, 2012). The Mann-Kendall statistic $(M)$ is a non-parametric method and is calculated as

$$
M=\sum_{k=1}^{n-1} \sum_{j=k+1}^{n} \operatorname{sgn}\left(P_{j}-P_{i}\right)
$$

where $n$ is the number of data locations. Machiwal and Jha (2012) suggests that even $n$ values as low as 10 can be used in Man-Kendall 's test provided there are no too many tied values. Supposing that $x=P_{j}-P_{i}$, then $\operatorname{sgn}(x)$ is estimated as

$$
\operatorname{sgn}(x)= \begin{cases}1, & \text { if } x>0 \\ 0, & \text { if } x=0 \\ -1, & \text { if } x<0\end{cases}
$$

The $M$ statistic represents the positive and negative differences for all data samples under consideration. The mean of the statistics under the null hypothesis is zero and is given as $\mathrm{E}[\mathrm{M}]=0$ while its variance $(\sigma)$ is given as

$$
\sigma=\frac{n(n-1)(2 n+5)-\sum_{k=1}^{n}\left(t_{j}-1\right)\left(2 t_{j}+5\right)}{18} .
$$



95\% confidence level.
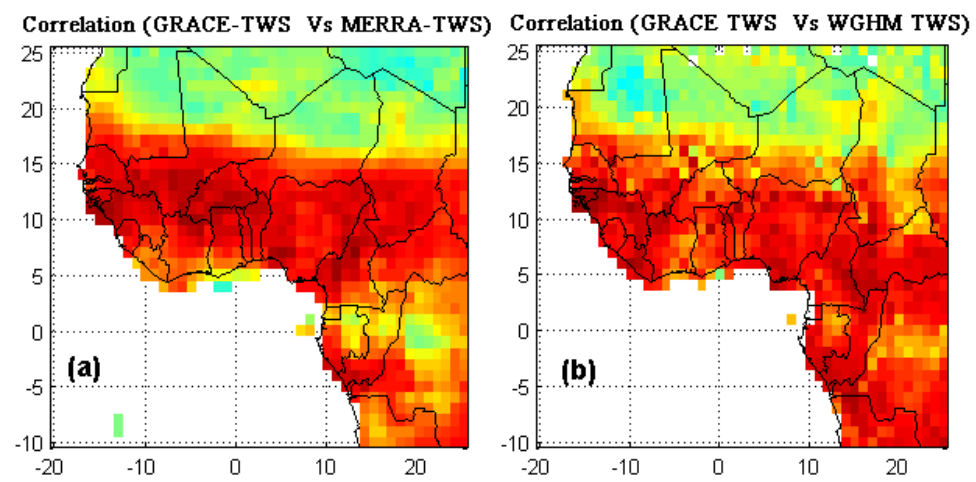

The null hypothesis (no trend), $H_{0}$, was tested at $\alpha=0.05$ (95\% confidence level). If the computed absolute value of the test statistics is greater than the critical value of the standard normal distribution, the hypothesis of negative or positive trend cannot be rejected at the

Figure 2: Correlation results for TWS products and the two precipitation products over TWA. (a) GRACE and MERRA TWS (2002 - 2014) (b) GRACE and WGHM TWS (2002 - 2009) and (c) GPCC and CHIRP $(1980-2014)$.

\subsection{Pre-validation of the reanalysis and model data}

In order to examine the strength of agreement between two different hydrological variables (e.g., GRACE-derived TWS and MERRA-based TWS), the Pearson's correlation coefficient was used while cross-correlation was employed to determine the time lag between the hydrological signals (e.g., precipitation and GRACE-derived TWS). Whereas these TWS products (MERRA and WGHM) were compared with GRACE-TWS, CHIRPS data was pre-validated by comparing it with GPCC gauge precipitation (Fig. 2). This is needful for data scarce regions such as TWA, particularly to help explore the increasing model and reanalysis data for hydrological applications. Also, this pre-validation effort is a milestone that provides insights as to the potential of these products for hydrological applications in TWA. The good correlation indicated in Figs. 2a-b, suggests that the spatial and temporal dynamics of MERRA and WGHM TWS products are consistent with GRACE-TWS. However, as will be shown later in the study, WGHM-TWS is underestimated in the region compared to MERRA-TWS. The CHIRPS precipitation data on the other hand shows a considerable strong consistency and agreement with GPCC-based precipitation in the region except in the extreme north-west Sahel (the Sahara Desert) (Fig. 2c). The GRACE-MERRA and 
GPCC VS GRACE-TWS

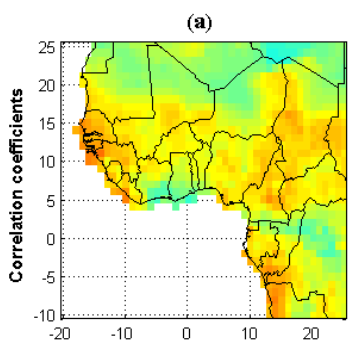

(b)
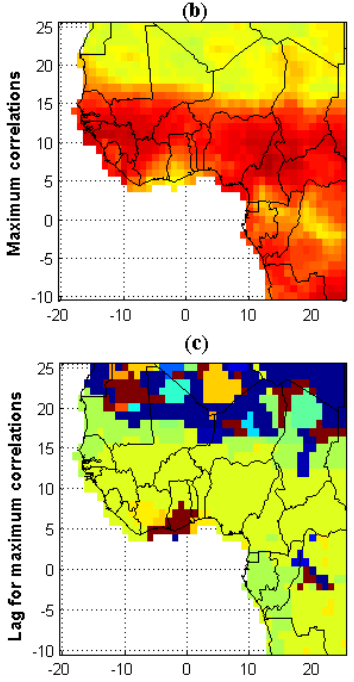

CHIRPS VS GRACE-TWS
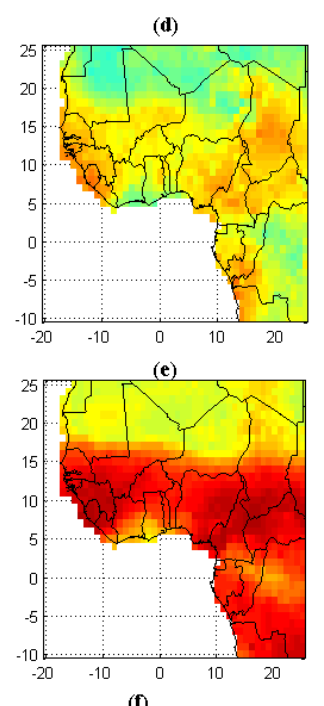

(f)

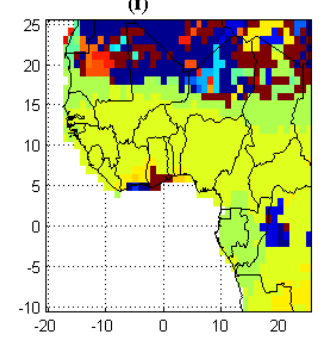

GPCC Vs MERRA-TWS

(g)

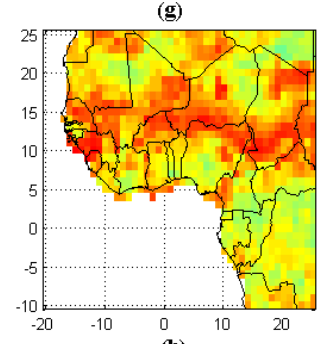

(h)
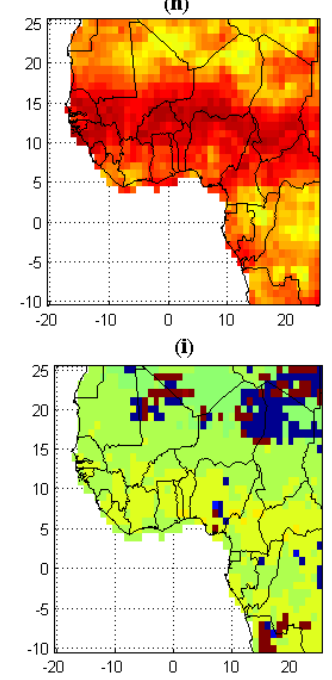

CHIRPS VS MERRA-TWS
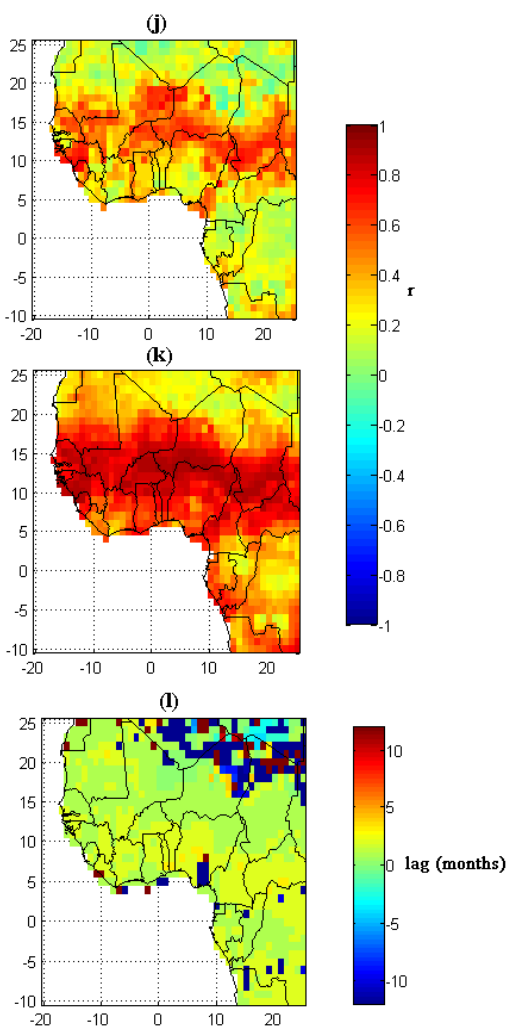

Figure 3: Spatial relations of rainfall (GPCC and CHIRPS) to stored water (MERRA and GRACE) over tropical West Africa (TWA) based on correlation analysis during a common period. (a)-(c) GPCC Vs GRACE TWS (2002 - 2014), (d)-(f) CHIRPS Vs GRACE TWS (2002 - 2014), (g)-(i) GPCC Vs MERRA TWS (1981 - 2014), and (j)-(l) CHIRPS Vs MERRA TWS (1981 - 2014).

Controlled numerical experiments based on climate modelling have been performed as part of a coordinated effort to create proxy data (e.g., Paolino et al., 2012; Rienecker et al., 2011; Koster et al., 2004; Robock et al., 2000) that are true representations of land surface conditions and can be used to study hydrological processes. Therefore, the relationship of GPCC and CHIRPS based precipitation with MERRA and GRACE TWS over the region is also examined to understand how GPCC and CHIRPS are associated with TWS (MERRA and GRACE) in the region both in the long term $(1980-2014)$ and short term (2002 - 2014). This relationship is useful in optimising and initializing not only weather or climate models but also in the representation of physical phenomena in hydrological models. The precipitation-GRACE-derived TWS relationship are consistent and shows that GPCC 
and CHIRPS products leads TWS by two month in much of the region that excludes the northern Sahel (Figs. 3a-f). Towards the extreme north of Sahel where the Sahara Desert is located, precipitation lags TWS due to arid conditions (Figs. 3c/f/i/l). The precipitationMERRA-derived TWS relationship shows stronger correlation coefficients in the Sahel, in addition to indicating a two month lag over much of the region (Figs. 3g-1). Unlike the maximum correlations of GRACE-TWS with GPCC and CHIRPS (Figs. 3b and e), maximum correlations of MERRA-TWS with GPCC and CHIRPS (Figs. 3h and k) are poor in the central Congo basin (i.e., the Democratic Republic of Congo-DRC) possibly due to the absence of groundwater in the MERRA TWS data and perhaps the sparse in-situ networks for model validation. Despite the uncertainty in reanalysis data (e.g., Rienecker et al., 2011), the association of GPCC and CHIRPS with MERRA TWS in the Sahel (Figs. 3g and j) are indications of the suitability of MERRA-TWS in semi-arid regions for hydrological applications.

\section{Results and Discussion}

4.1. Long-term spatio-temporal variability of precipitation and land water storage (19802015)

In this section, the spatio-temporal evolutions of leading precipitation and land water storage (soil moisture, groundwater, and TWS) modes for the 1980 - 2015 period over TWA (tropical West Africa) are discussed. This is done to understand both the characteristics and homogeneous regions with strong leading patterns of variability in the region.

\subsubsection{Changes in precipitation}

The coastal West African countries (Fig. 1) have strong seasonal rainfall patterns as opposed to the Sahel region (Fig. 4). Apart from the JFM period (Fig. 4a), which indicates the presence of relatively large amount of rainfall only in the Equatorial countries (i.e., Congo, Gabon, Equatorial Guinea, and DRC), the presence of considerable rainfall can be seen all through the year (i.e., from all seasonal windows-Figs. 4b-f) in some of the coastal countries (Guinea Coast region). West Africa is typically active hydrologically because of a plethora of physical phenomena that modulates its climate system. The West African monsoon (WAM) circulation, for instance, modulates the seasonal northward displacement of the intertropical convergence zone (ITCZ) and remains the principal source of precipitation over a large part of West Africa (Boone et al., 2009). In addition to this, the La-Niña and ElNiño cycles play important roles in the variability of rainfall in West Africa (e.g., Paeth et al., 2012; Nicholson et al., 2000), triggering considerable large amplitudes of rainfall within few months and extreme dry periods. As is the characteristics of tropical systems, rainfall in West Africa is characterised by strong seasonal inter-annual variations. This kind of variability, as 

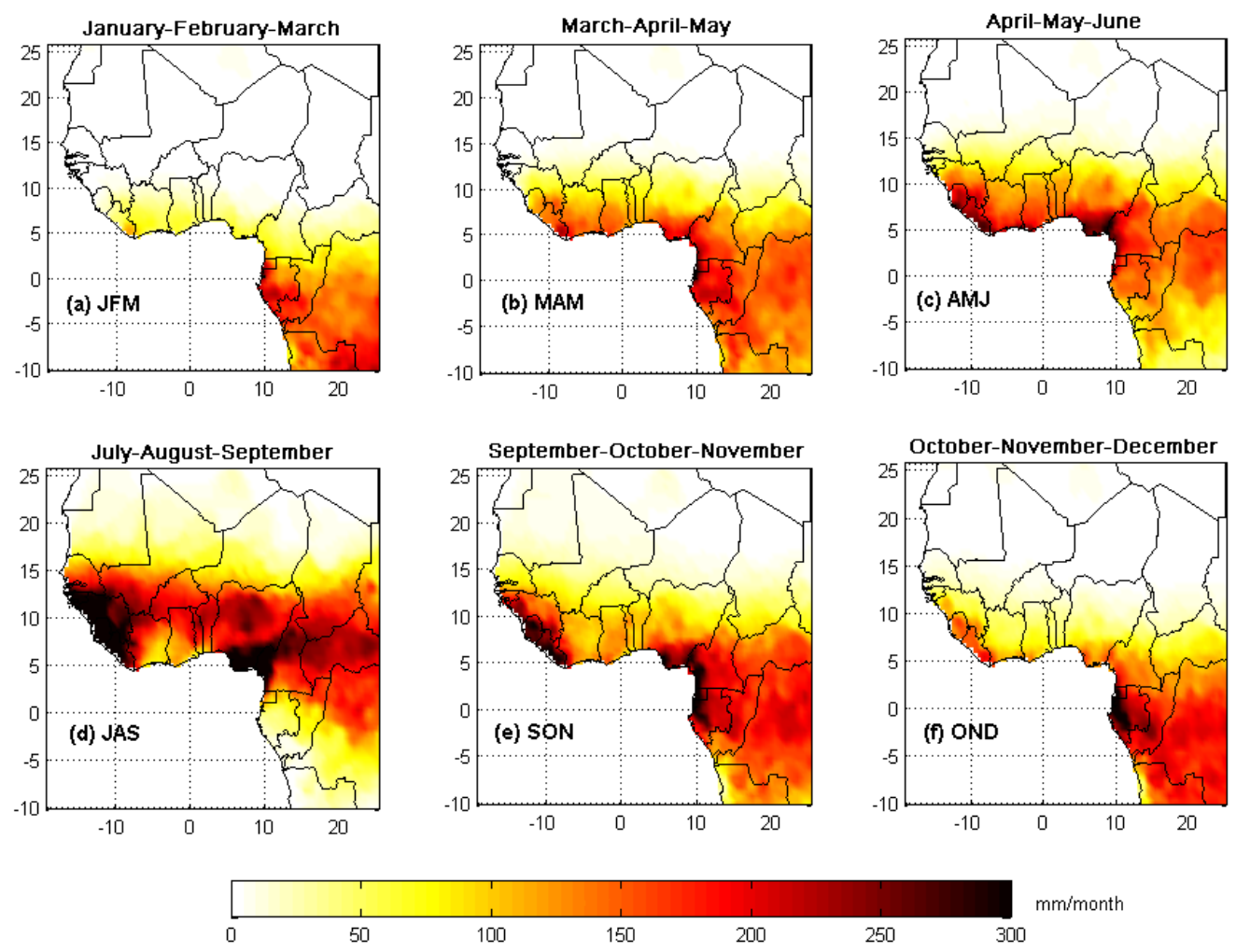

Figure 4: Seasonal mean variability of precipitation (GPCC version 7) during 1980 - 2014 period in tropical West Africa (TWA). The seasonal categories are indicated as (a) January-February-March (JFM), (b) MarchApril-May (MAM), (c) April-May-June (AMJ), (d) July-August-September (JAS), (e) September-OctoberNovember (SON), and (f) October-November-December (OND).

indicated in Hall et al. (2014), increases the likelihood of multi-year droughts and disastrous flash floods.

On the spatial and temporal dynamics of rainfall over tropical West Africa (TWA), the two leading modes of GPCC and CHIRPS-based precipitation over TWA accounts for about $70.4 \%$ and $80.3 \%$ of the total variability, respectively (Fig. 5). These leading EOF modes of rainfall variability from both data in TWA creates two homogeneous regions defined by similar temporal and spatial patterns. The strong magnitudes of variability (i.e., large amplitudes) in these leading modes show maximum loadings in regions where strong annual amplitudes in soil moisture, groundwater, and TWS have also been observed (Sections 4.1.2 and 4.1.3 ). Whereas the leading EOF (spatial patterns) shows rainfall anomalies with opposite signs to the north and south of $0^{\circ} \mathrm{N}$, the second EOF mode indicates a contrast of rainfall anomalies with opposite signs to the north and south of $10^{\circ} \mathrm{N}$. Specifically, the first mode highlights the annual variability of rainfall (PC1, Fig. 5) for the West African region (i.e., Sahel and Guinea coast countries) and a dipole pattern in the Equatorial region (e.g., Gabon, Cameroon, Congo, and Democratic Republic of Congo-DRC, see Fig. 1 for the respective countries). The second rainfall mode on the other hand, highlights multi-annual variations of rainfall in the Guinea coast countries and the Equatorial region (PC2, Fig. 5). Observed EOF loadings of this mode in southern Cameroon, Gabon, and Equatorial Guinea are the 

spatial patterns of rainfall are observed between July and September.
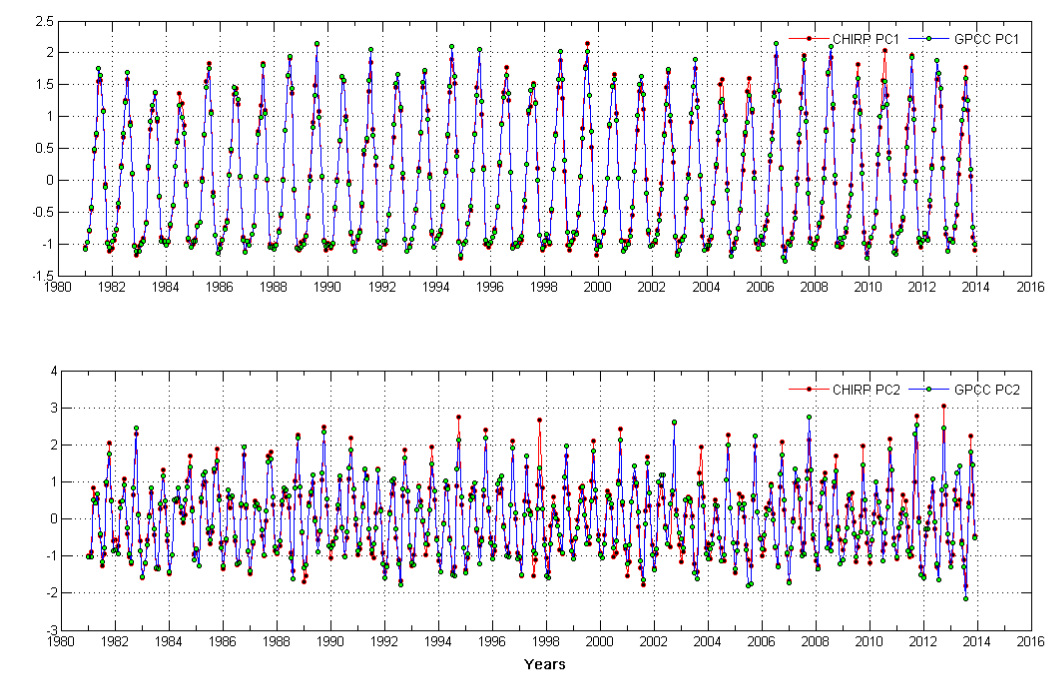
Odekunle and Eludoyin, 2008).

strongest in TWA. The temporal patterns of this second mode indicate a bimodal structure in rainfall (receiving annual rainfall twice in a year) over the coastal areas of TWA. Generally, rainfall in these areas have been linked to the latitudinal movement of the tropical rainbelt, and the influence of SST amongst other factors (e.g., Mohino et al., 2011b; Nicholson, 2008;

The spatial variability of rainfall as observed in these dominant patterns are much similar to the observed amplitudes and seasonal distribution of rainfall (Fig. 4d). Furthermore, the strong EOF loadings (GPCC and CHIRPS EOF1, Fig. 5) observed between latitudes $8^{\circ} \mathrm{N}$ and $12^{\circ} \mathrm{N}$ (the Sahel) are largely indicative of the considerable changes in annual precipitation of West Africa during the July-September period. The temporal evolutions (GPCC and CHIRPS PC1, Fig. 5) of the corresponding leading EOF loadings show that the maximum peaks of precipitation are observed in August and sometimes in September. This is also largely consistent with the seasonal distribution of rainfall indicated in Fig. 4d, where strong
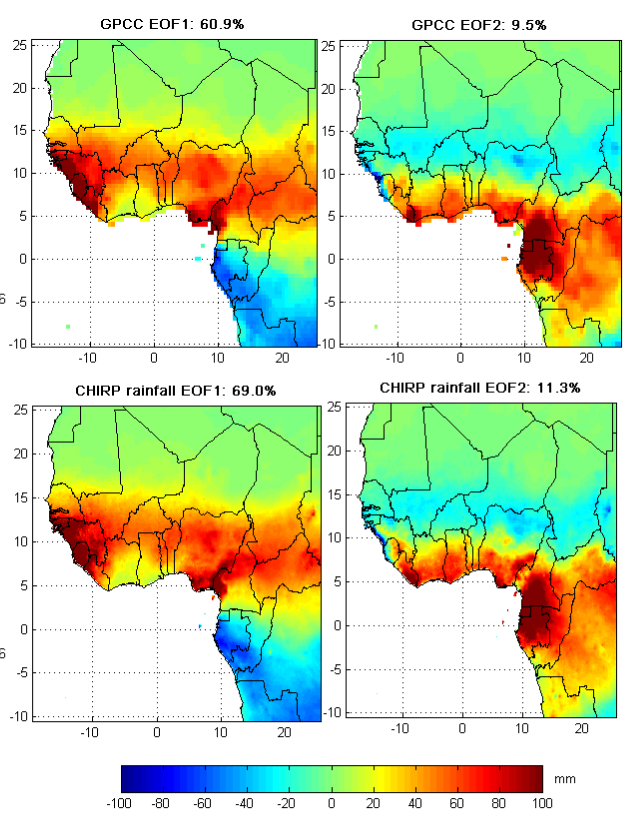

Figure 5: PCA decomposition of CHIRPS and GPCC-based precipitation (1980-2014) over TWA. The EOFs (right) are loadings showing spatial patterns of variations in precipitation over TWA while the corresponding PCs (left) are temporal variations, which are normalised using their standard deviation to be unitless. The variances explained by each PCA mode, which are expressed in percentages are also shown.

Some studies have indicated that this rainfall mode (PC1/EOF1, Fig. 5) dominates the summer West African rainfall variability and is highly coupled to Equatorial Atlantic SST (e.g., Losada et al., 2010; Janowiak, 1988). Whereas this same rainfall mode has been acknowledged to be representative of the entire Sahel-Sudan region by Fall et al. (2006), Nicholson and Palao (1993) identified three spatial modes of rainfall variability that describes the regional climate of West Africa, arguing that the Sahel cannot be treated as a homogeneous rainfall sector with other regions in West Africa. However, Sanogo et al. (2015) recently 
found no justification for further subdivision of the Sahel rainfall as their EOF analysis yielded two homogeneous rainfall zones (i.e., Sahel and Guinea Coast). Such contrast, primarily could emanate from the size of the spatial domain sampled and the climatological period examined. For instance, Mohino et al. (2011b) explored the characteristics of the inter-annual variability of West African rainfall (i.e, June-September rainfall only). Their observational EOF analysis for the 1957 - 1978 period showed that the leading EOF mode ( $11 \%$ of the total variance) had its maximum loadings concentrated over the Sahel whereas the second EOF mode (7\% of the total variance) exhibited inter-annual signals in the temporal patterns with maximum loadings over the Guinea Coast. This current analysis included all monthly precipitation because of the diversity in local climates and the fact that precipitation is highly variable with strong presence in all seasonal time scales in coastal and humid TWA (Figs. 4a-f). Over West Africa (i.e., Lat $0^{\circ} \mathrm{N}-20^{\circ} \mathrm{N}$ and Lon $20^{\circ} \mathrm{W}-20^{\circ} \mathrm{E}$ ) and the surrounding ocean, the two leading modes of TRMM-based precipitation $(2002-2014)$ as shown in Ndehedehe et al. (2016a), accounted for $61.7 \%$ of the total variability. But when the surrounding ocean has been masked out and the domain analysis extended to include Equatorial countries of the Congo basin (i.e., between Lat $25^{\circ} \mathrm{N}$ and $10^{\circ} \mathrm{S}$ ), the cumulative variance for the two leading modes increase to $70.4 \%$ and $80.3 \%$ for GPCC and CHIRPS based precipitation $(1980-2014)$, respectively, confirming the influence of domain size and probably the length of data record on the explained variance.

Essentially, the leading rainfall mode observed in TWA (GPCC and CHIRPS EOF1/PC1, Fig. 5), which has strong EOF loadings over West Africa adequately describes the interannual variability of rainfall in the region, consistent with previous studies (e.g., Fontaine and Bigot, 1993; Janicot, 1992; Janowiak, 1988), and is generally appropriated by decision makers for planning purposes as reported by Fall et al. (2006). This is because the dominant rainfall mode represents the main climatological properties and changes in the region. For instance, the well known droughts of 1983/1984, which were continental in scale are marked out in the amplitudes of the temporal evolutions (PC1, Fig. 5). Based on the observed peak amplitudes (PC1, Fig. 5), extreme wet and dry years (e.g., 1982/1983, 1997/1998, 1988/1989, 1994/1995, etc.) caused by the strong impacts of El-Niño (e.g., 1982/1983) and La-Niña (e.g., 1998/1999) cycles can also be identified in the temporal evolutions of the first rainfall mode. The second rainfall mode also show hydro-climatological events in TWA that are similar to the first rainfall mode. For example, the amplitudes of PC2 in 1983 (Fig. 5) confirms the prominent drought event over the continent that was forced by high Indian Ocean SST (Bader and Latif, 2011), and in addition identifies years with the lowest summer rainfall (e.g., 1987). Years with relatively low rainfall (e.g., 1991, 2001 and 2008) in this mode are characterised with less pronounced amplitudes (i.e., for both the first and second rain) while extreme wet years $(1994,1997,2007,2011 / 2012)$ show strong pronounced maximum 
amplitudes (PC2, Fig. 5). These two modes of rainfall variability are the major drivers of land water storage in TWA.

\subsubsection{Changes in soil moisture}

Soil moisture is a critical and highly variable component of the hydrological cycle. Because of its strong influence on hydro-meteorological processes within the atmospheric boundary layer (Petropoulos et al., 2015), and role in land-atmosphere coupling (e.g., Koster et al., 2004), soil moisture is a major land state variable that can be used to study changes in global climate and weather systems. In this section, the temporal and spatial dynamics of CPC model and MERRA-reanalysis long term soil moisture data over TWA are discussed. These spatio-temporal patterns of soil moisture are based on the PCA technique (Section 3) and is more robust compared to analysing regional averages of soil moisture as done in Douville et al. (2007). The two dominant modes of variability in CPC and MERRA soil moisture products resulted in homogenous regions that describe the spatio-temporal variability of soil moisture over TWA. These leading modes accounted for a total variability of $70.8 \%$ and $71.9 \%$ for CPC and MERRA soil moisture products, respectively (Fig. 6). Similar to rainfall, the first orthogonal modes represent annual signals (PC1/EOF1, Fig. 6) while the second orthogonal modes show multi-annual variations in the Equatorial region (PC2/EOF2, Fig. 6). Interannual variability appears to be a prominent feature characterising the dominant temporal evolutions of both soil moisture products (PC1, Fig. 6). The significantly less pronounced amplitudes of both soil moisture products in 1983/1984, 1991, 1997, and during the $2000-$ 2006 period over TWA are consistent (PC1, Fig. 6). Some regions in West and Central Africa experienced relatively low precipitation, water deficits, and drought conditions during this periods (see, e.g., Ndehedehe et al., 2016b,c; Asefi-Najafabady and Saatchi, 2013), confirming the strong land-atmosphere interaction of the region (Koster et al., 2004).

From the temporal evolutions of the CPC and MERRA soil moisture products, a long term decline is observed between 1986 and 2008 in the second mode (PC2/EOF2, Fig. 6). The observed sharp decline between 1995 and 2005, (about $16 \mathrm{~mm} / \mathrm{month}$ estimated from the CPC model soil moisture) represents about two decades of consistent shift in regional soil moisture of the Equatorial countries (PC2/EOF2, Fig. 6). Although rainfall indicated no decline during the same period ( $\mathrm{PC} 2 / \mathrm{EOF} 2$, Fig. 5), observed decline in evapotranspiration (ET) during the $2000-2014$ period (not shown) over much of the Congo basin confirms the limited moisture supply in the region. Interestingly, a study on global evapotranspiration trends (see, Jung et al., 2010) showed that the decline in global land evapotranspiration (1998 - 2008) was largely consistent with decline in soil moisture. As discussed further in Section 4.1.4, analyses of long term trends in TWS and soil moisture (1982-2014) at the pixel scale over TWA confirm this decline in the temporal series of soil moisture over the Congo basin and is consistent with decline in land surface temperature over the basin. Focusing on 

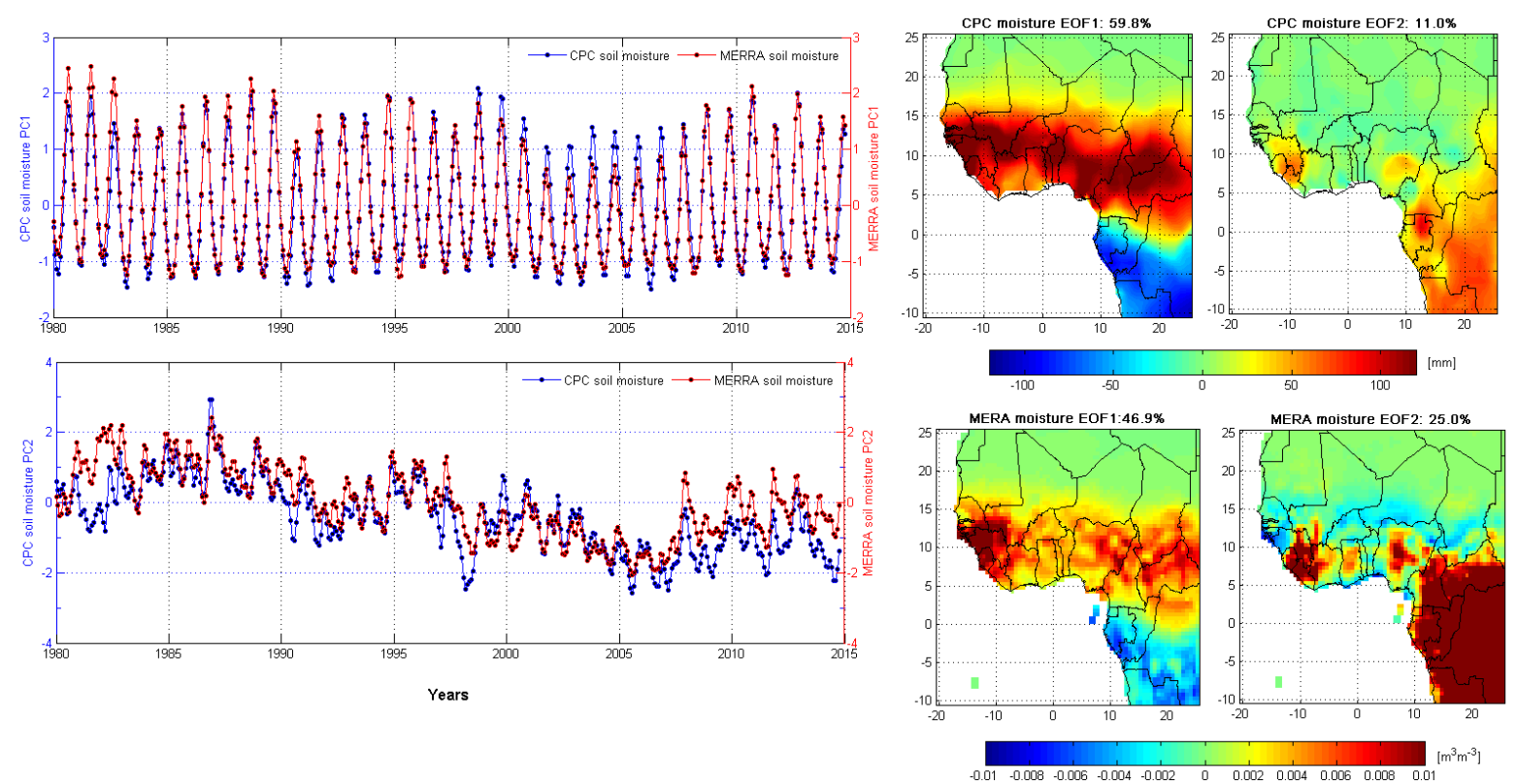

Figure 6: PCA decomposition of CPC model $(\mathrm{mm})$ and MERRA reanalysis $\left(\mathrm{m}^{3} \mathrm{~m}^{-3}\right)$ based soil moisture products over TWA for the 1980 - 2014 period. The EOFs (right) are loadings showing spatial patterns of variations in soil moisture over TWA while the corresponding PCs (left) are temporal variations, which are normalised using their standard deviation to be unitless. The variances explained by each PCA mode, which are expressed in percentages are also shown.

the evolving trends of soil moisture in the last decade $(2003-2014)$, short term trends are here reported for the temporal patterns of CPC soil moisture (trends are in normalised units for simplicity but can be adjusted to original units through multiplication with the EOFs). This choice was made to help relate soil moisture changes to those of GRACE-TWS in the Congo basin as it is one of the focus region in this study. A decline of $0.51 \pm 0.09$ during the $2003-2006$ period and an increase of $0.09 \pm 0.06$ between 2006 and 2009 for soil moisture are observed (PC2, Fig. 6). Furthermore, declines of $0.28 \pm 0.17$ and $0.37 \pm 0.11$ were observed in the periods of $2010-2011$ and $2013-2014$, respectively (PC2, Fig. 6). Interestingly, the observed trend for PC2 of Fig. 6 (i.e., a decline of $0.51 \pm 0.09$ ) coincides with the second orthogonal mode of GRACE-derived TWS (PC2, Fig. 7) in Section 4.1.3, which indicates a decline of $0.58 \pm 0.15$ during the same period (i.e., 2003 and 2006). Except for the period between 2012 and 2014, the positive and negative trends indicated for the periods during 2006 - 2009 and 2010 - 2011, respectively, for CPC model soil moisture (PC2, Fig. 6), are consistent with those of GRACE-TWS (PC2, Fig. 7). The actual values of the observed declining trends during the 2003 - 2006 period for GRACE-derived TWS and soil moisture second PCA modes (PC2, Figs. 6 and 7), when jointly derived from their corresponding EOFs are estimated as $\backsim-78.4 \pm 20.3 \mathrm{~mm} / \mathrm{yr}$ and $\backsim-45.9 \pm 8.1 \mathrm{~mm} / \mathrm{yr}$, respectively. This loss of soil moisture $(\rho<0.05)$ during the period of $2003-2006$ (PC2, Fig. 6) points toward the significant role and contribution of soil moisture changes to observed GRACE-derived 
TWS variations in the Equatorial countries of TWA. Although the MERRA TWS is in volumetric units, it indicates similar trends in the observed temporal patterns as the CPC model soil moisture (PC2, Fig. 6).

The long term decline in multi-annual variation of soil moisture (i.e., from 1986 to 2008) observed in these Equatorial countries (PC2, Fig. 6) could be the cause of the observed decline in vegetation greenness of the Congolese forest (Zhou et al., 2014). The spatial variations of soil moisture, TWS, and rainfall trends over TWA (see Section 4.1.4) confirm a long term drying in these Equatorial countries, consistent with the observed soil moisture modes of variability in this section. In the cuvette central of the Congo basin, Zhou et al. (2014), in a bid to justify the weak correlations between rainfall and GRACE-TWS, reported that GRACE-TWS changes in tropical regions represents changes mainly in surface water and groundwater and that the response of GRACE-TWS to rainfall could not have emanated from the small scale and short-term rainfall anomalies. However, the PCA analysis of CPC model soil moisture indicates total variability of $11.0 \%$ (PC2, Fig. 6), which to a very large extent is consistent with GRACE-TWS total variability of 10.5\% (see Section 4.1.3, as well as PC2, Fig. 7) in the Congo basin (countries in Equatorial Africa). Hence, this study argues that GRACE-TWS changes in the Congo basin also represent significant changes in soil moisture, in addition to surface water and groundwater as earlier reported (e.g., Lee et al., 2011).
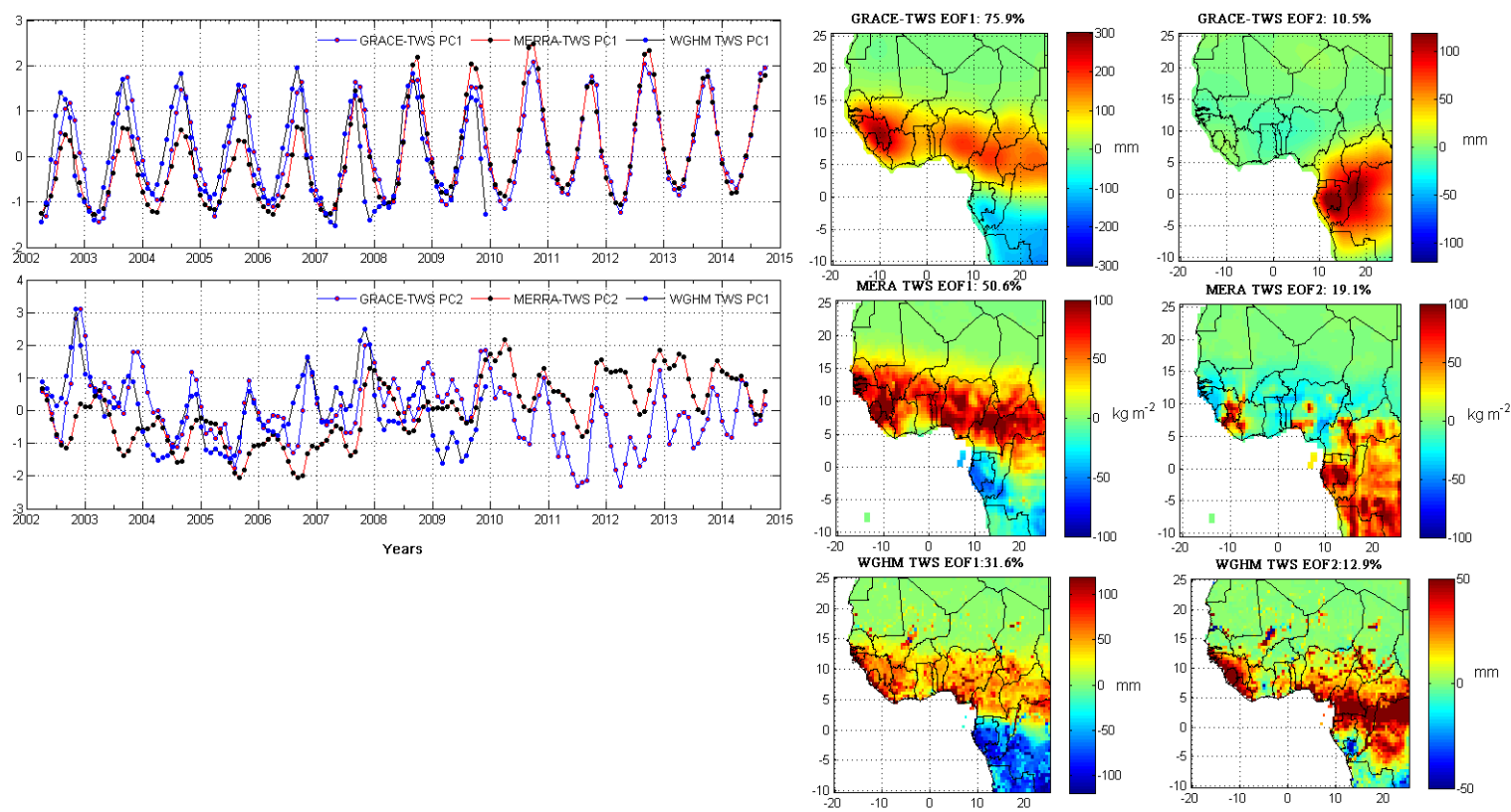

Figure 7: Comparing the space-time evolutions of MERRA (2002 - 2014) and WGHM-based TWS (2002 2009) products over TWA with GRACE-derived TWS (2002-2014). The EOFs (right) and the corresponding temporal patterns or PCs (left) are constructed similar to Fig. 6. The space-time evolutions of GRACE-TWS covers TWA (including Central African countries and the Congo basin) and is updated from a previous report which, focused on West Africa (Ndehedehe et al., 2016a). 


\subsubsection{Terrestrial stored water}

As an update to the analysis of GRACE-derived TWS over West Africa during the 2002 - 2014 period (see, Ndehedehe et al., 2016a), the spatio-temporal evolutions of long term reanalysis and model derived TWS over TWA in the last 3.5 decades are discussed in this section. Before then, the variability of these TWS products in space and time have been compared with those of GRACE-derived TWS based on their PCA results over TWAtropical West Africa (Fig. 7). The PCA results for the GRACE-derived TWS indicate strong dominant patterns (i.e., annual signal) in the first EOF, which represents total variability of $76 \%$ mainly from the countries between latitudes $8^{\circ} \mathrm{N}$ and $15^{\circ} \mathrm{N}$ (PC1, Fig. 7). Be it West Africa or the entire TWA (cf. Fig. 1), this mode of GRACE-TWS is the dominant and shows the strongest EOF loadings in Guinea with an increasing trend in the corresponding temporal evolution (PC1, Fig. 7). Also interesting is the dipole pattern in the EOF loadings of GRACE-TWS (EOF1, Fig. 7), which is consistent with those of rainfall and soil moisture (Sections 4.1.1 and 4.1.2).

The presence of surface waters (e.g., lakes, reservoirs, and rivers), soil moisture, and groundwater in West Africa (especially the Guinea Coast countries) are major components of GRACE-TWS, which unarguably are driven by rainfall. In particular, reservoir systems (surface water schemes) and lakes have shown strong and considerable impacts on hydrological changes of river basins in Africa (e.g., Ndehedehe et al., 2017a; Moore and Williams, 2014). In the Volta basin, for example, increasing trends in GRACE-TWS changes were found to be inconsistent with rainfall due to the impacts of a large water project-the Akosombo dam (e.g., Ndehedehe et al., 2017a; Ahmed et al., 2014). But the observed increase in GRACE-TWS, which is relatively stronger in Guinea because of the EOF loadings (PC1, Fig. 7), emanates mostly from extended wet seasons and strong seasonal precipitation changes (cf. Figs. 4c-e). With lower evapotranspiration rates in such region (not shown) and strong amplitudes in precipitation (Figs. 4d and 5), increased water storage and inundated areas are more likely to occur. The second mode of GRACE-TWS observed over the Congo basin, which was not part of the earlier report in Ndehedehe et al. (2016a), accounts for $10.5 \%$ of the total variability over TWA. Whereas this variance explained is somewhat consistent with the second modes of rainfall (GPCC) and soil moisture (CPC model) variability over TWA (Sections 4.1.1 and 4.1.2), this does not imply that rainfall is a prominent driver of GRACE-TWS in this region as river discharge at the Congo Kinshasa station shows stronger association with the observed temporal evolutions in this mode. This will be discussed in detail in Section 4.2 .

Meanwhile, the first mode of MERRA-TWS (PC1, Fig. 7) agrees strongly with GRACETWS, indicating a correlation of 0.91 compared to WGHM-TWS (0.81). But in the second mode (PC2, Fig. 7), WGHM-TWS is more associated with GRACE-TWS $(r=0.57)$ com- 
$$
\text { decades. In parallel, the WGHM groundwater changes over TWA are also analysed. }
$$
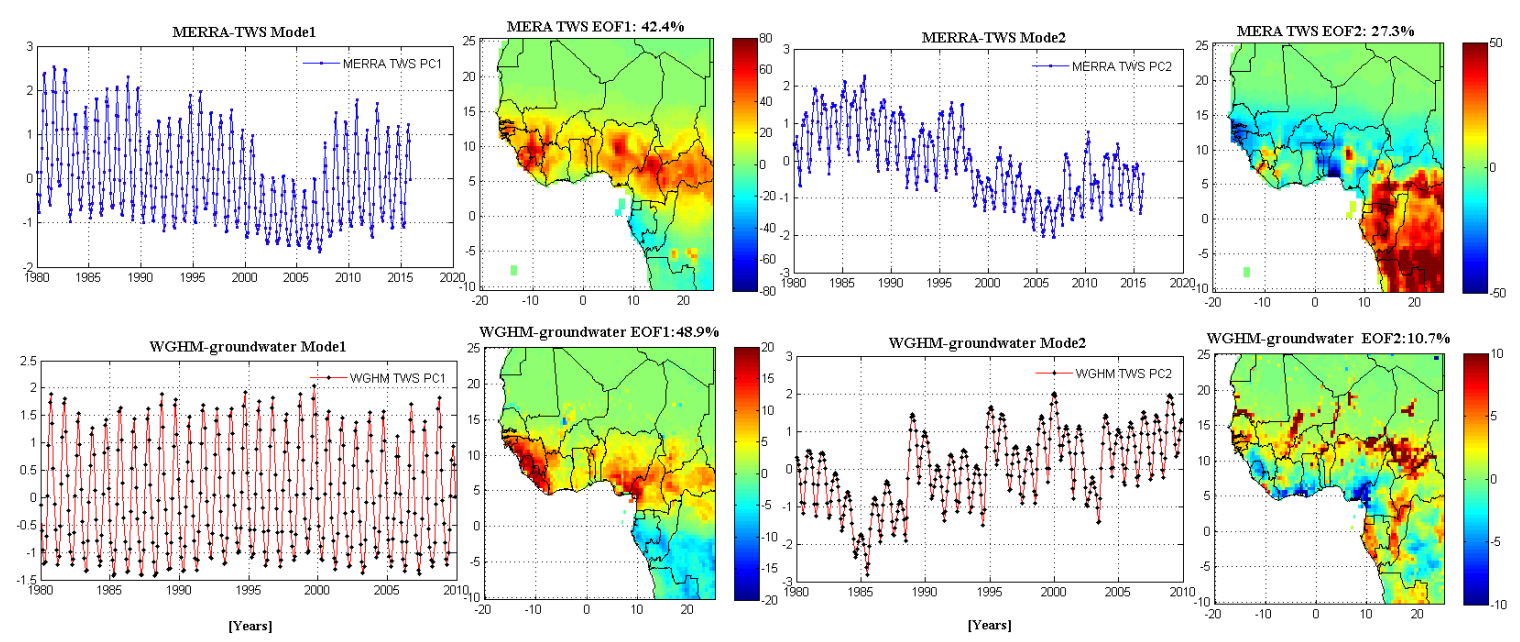

Figure 8: PCA decomposition of MERRA (1980 - 2015) and WGHM-based groundwater (1980 - 2009) over TWA. The EOFs are loadings showing spatial patterns of variations in TWS $\left(\mathrm{kg} \mathrm{m} \mathrm{m}^{-2}\right)$ and WGHMgroundwater $(\mathrm{mm})$ over TWA while the corresponding PCs are temporal variations, which are normalised using their standard deviation to be unitless. Row 1 shows the first and second modes of MERRA-TWS (temporal evolutions and their corresponding spatial patterns) while row 2 indicates the first and second modes of WGHM groundwater (temporal evolutions and their corresponding spatial patterns). The variances explained by each PCA mode, similar to Figs. 5 and 6 are also indicated.

The MERRA-TWS show relatively strong spatial patterns in West Africa and the Equatorial countries for the first mode (42.4\% variance) and second mode (27.3\% variance), respectively (Row1, Fig. 8). The first mode of WGHM groundwater changes over TWA on the other hand, accounts for $48.9 \%$ of the total variability, with relatively strong spatial patterns in West Africa (Guinea, Liberia, Sierra Leone, and Nigeria) while the second mode accounts for $10.7 \%$ of the total variability (Row2, Fig. 8). The time series of MERRATWS associated with the band of EOF loadings over West Africa (Row1, PC1, Fig. 8) show strong inter-annual fluctuations with the lowest peak amplitudes (deficit conditions) 
observed during the $2001-2006$ period. The overall picture of this temporal evolutions (MERRA-TWS PC1, Fig. 8) somewhat suggests a multi-decadal variability, but apparently indicates the 2001 - 2006 period as the driest and hydrological drought years in West Africa and is consistent with previous studies in West and Central Africa (e.g., Ndehedehe et al., 2016a; Asefi-Najafabady and Saatchi, 2013). For the second MERRA-TWS mode (Row1, PC2, Fig. 8), considerable EOF loadings are observed over the Equatorial countries while its corresponding temporal patterns indicate a strong decline (about $26 \mathrm{~kg} \mathrm{~m}^{-2} / \mathrm{month}$ ) during the $1985-2005$ period that is consistent with observed soil moisture declines (PC2, Fig. 6). The estimated trends in MERRA-TWS temporal patterns (Row1, PC2, Fig. 8) as compared with GRACE-TWS (PC2, Fig. 7) during the 2003 - 2006 period are somewhat close $(0.58 \pm 0.15$ and $0.50 \pm 0.10$, for MERRA-TWS and GRACE-TWS normalised units, respectively). The observed trends in MERRA-TWS over the Congo basin should, however, be interpreted with caution because of the slight restriction of MERRA data observed in the region (cf. Figs. 2a-c).

In the long term WGHM groundwater statistical decomposition, the leading patterns of WGHM groundwater indicate annual and multi-annual variations in their temporal series, i.e., $\mathrm{PC} 1$ and $\mathrm{PC} 2$, respectively (Row2, Fig. 8). It is rather interesting that regions of observed spatial variability (EOF loadings) in groundwater are consistent with areas in West Africa that receive the highest rainfall (cf. Figs. 4d and 5). The lowest maximum peaks in the amplitudes of the time series associated with the EOFs of WGHM groundwater mode1 (Row2, PC1, Fig. 8) are observed in 1983, 2005, and 2009. These years are significant hydrological periods known for extreme drought conditions and matches some meteorological records and reports for case-specific studies in West Africa (e.g., Ndehedehe et al., 2016b,c; Kasei et al., 2010). Unlike rainfall, soil moisture, and TWS, relatively strong spatial patterns of WGHM groundwater over TWA in the second mode are mostly observed in the Sahel region of West Africa. (Row2, PC2, Fig. 8). Countries in the Lake Chad basin-LCB (e.g., southern Chad and north-east Nigeria) show relatively strong spatial variability with their associated temporal patterns indicating trends in groundwater (Row2, PC2, Fig. 8). Except for the $1980-1985$ period where the strong decline in groundwater is a response to the extreme drought of $1983 / 1984$, substantial increase in groundwater during the $1985-2000$ and $2003-2009$ periods are pointers to potential groundwater resources of the LCB. In Mali, Congo, and Equatorial Guinea, increase in groundwater are also observed (further details on trends are provided in the next section). The lowest minimum groundwater amplitude over TWA is observed in 1984/1985 (Row2, PC2, Fig. 8), notably the impact of the extreme drought of $1983 / 1984$ in the region. 

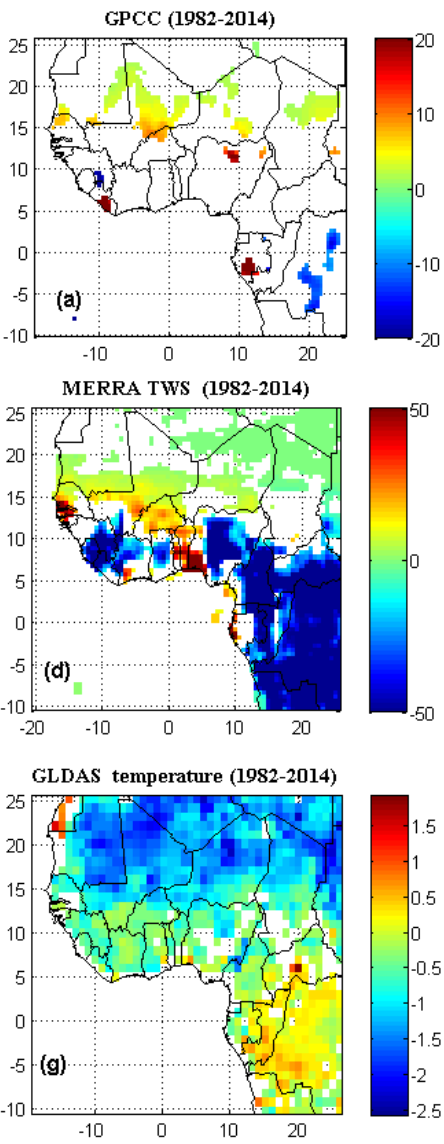
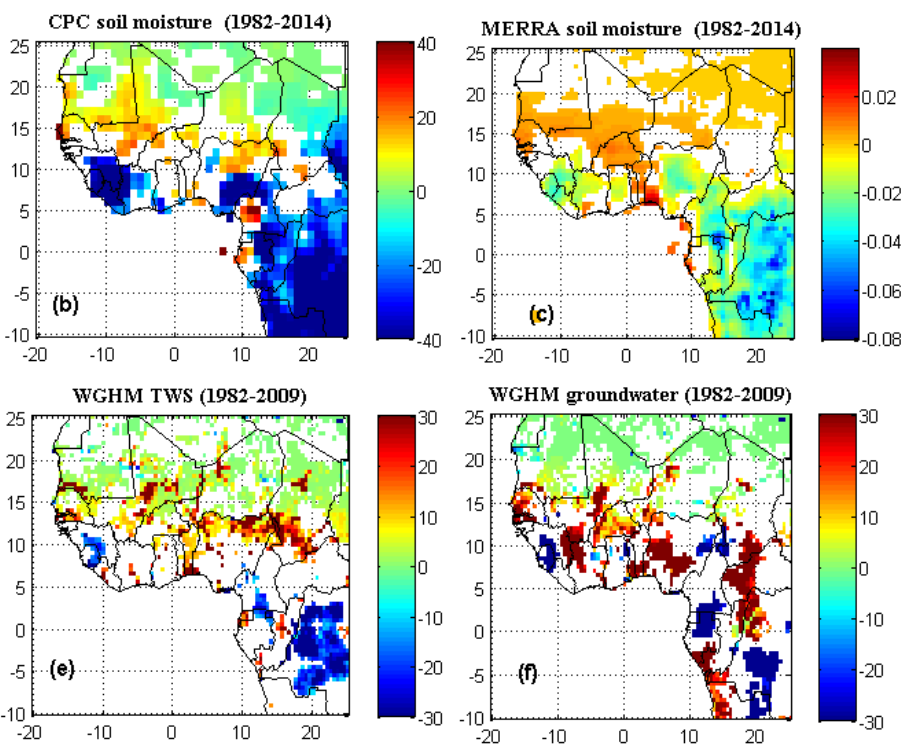

Figure 9: Spatial patterns of long term linear trends in (a) rainfall (1982 - 2014), (b)-(c) soil moisture (1982 - 2014), (d)-(e) TWS (1982 - 2014), (f) groundwater (1982 - 2009) and (g) land surface temperature (1982 - 2014) over TWA. Unlike other data (GPCC, CPC moisture, MERRA, and GLDAS), the WGHM derived TWS covers the $(1982-2009)$ period. Only statistically significant trends $(\rho<0.05)$ are presented and they are estimated in mm/yr. The MERRA soil moisture product is in $m^{3} m^{-3} / \mathrm{yr}$ while temperature is estimated in DegC/yr.

The long term trends in precipitation, TWS, soil moisture, and model groundwater were estimated for each grid points over TWA for the common period except for the WGHM outputs $(1982-2009)$. The GPCC-based precipitation shows some pockets of positive trends in the Sahel, Liberia, and Equatorial Guinea (Fig. 9a). The trends in GPCC-based precipitation over the Sahel are somewhat consistent with observed positive trends in soil moisture, TWS, and groundwater (Fig. 9b-f). This would align with the two schools of thoughts on the hydro-climatic conditions of the Sahel: the 'Sahel greening' (e.g., Dardel et al., 2014; Boschetti et al., 2013; Olsson et al., 2005; Herrmann et al., 2005) and the recognised rainfall recovery in some parts of the Sahel (e.g., Nicholson, 2005; Lebel and Ali, 2009). Still within 
1950 - 2000 period.

Whereas the trends in the two soil moisture products (CPC and MERRA) and TWS (WGHM and MERRA) observed over West Africa are somewhat inconsistent, they tend to agree in the Equatorial countries (though WGHM shows negative trends mostly in DRC), indicating negative patterns during the period (Figs. 9b-e). The gross similarity in the spatial patterns of linear trends in soil moisture and TWS (between $40-60 \mathrm{~mm} / \mathrm{yr}$ ) over the Equatorial countries reveal the long term drying in the region. As rainfall is a principal component of the hydrological cycle, it is expected that long term changes in soil moisture should closely follow rainfall. But over the Equatorial regions, trends in rainfall (except in some parts of DRC and southern Gabon) are statistically insignificant (Fig. 9a) different from those of soil moisture products (Figs. 9b-c). Such disagreement may result from land surface conditions (e.g., temperature) or other meteorological processes. The former appears to be more critical in this case as statistically significant trends in temperature $(1982-2014)$ have been observed, see, e.g., Fig. 9g. The Equatorial countries show considerable warming unlike the Sahel that shows significant cooling during the period. The synergy between precipitation deficits or lack of a statistically significant positive trend in precipitation and long term warming of the land surface can restrict recharge of the soil column leading to strong deficits in TWS/soil moisture as observed in the countries of the Congo basin. As Jung et al. (2010) noted, the 1998 El-Nino event coincided with decrease in global land ET, which was largely caused by soil moisture deficits during the $1998-2008$ period. Climate change is expected to restrict the availability of freshwater and impact on the water resources sector. With the warming of the global oceans during the $1982-2014$ period (not shown), the concern on how such changes will impact on the region's land water storage is amplified. The interaction of the global ocean with TWS over TWA is discussed further in Section 4.3.

For obvious reasons such as the sensitivity of modeled land surface hydrology to forcing dataset that drives it (e.g., Sheffield and Wood, 2008), it is important to note that trends in these model and reanalysis soil moisture products would only be as strong as the historical meteorological data used in their forcing. In most cases, they are however, more reliable than satellite products (except GRACE data). Since uncertainties in the model and reanalysis data are likely, here, we focus more on the consistency of hydrological outcomes in each data to describe the observed changes during the period rather than an absolute value. Apparently, combining the result in Section 4.1.2 with this section, there is a strong evidence of a considerable loss in soil moisture in the Equatorial countries of TWA, which also aligns with some site-specific reports in the region. These observed trends in soil moisture, for example, coincide with the reported decline in vegetation greenness in the upper Congo basin (Zhou et al., 2014). Even more recently, long term drying (1950-2014) in Central Equatorial Africa has been reported by Hua et al. (2016). They identified SST variations over Indo-Pacific, and 
large scale circulation changes related to a weaker West African monsoon as major causes. Hydrological conditions of the Congo basin have shown some marked variability in recent times. Between 2002 and 2006, the Congo basin lost about $280 \mathrm{~km}^{3}$ of stored water as estimated from GRACE-TWS by Crowley et al. (2006) while observed declines in GRACE-TWS in three sub basins of the Congo river basin $(2003$ - 2012) where attributed to deforestation by Ahmed et al. (2014). The strong spatial distribution of negative trends in soil moisture and TWS over the Equatorial countries (Figs. 9b-e), which are consistent with the aforementioned case studies above are glaring evidence of acceleration and shifts in the hydrology of the region. On the other hand, WGHM groundwater increased substantially in most parts of TWA (Fig. 9f). To be noted is the spread in positive distribution of groundwater trends in some areas (Congo basin and some parts of West Africa) where GPCC precipitation and the soil moisture products indicated negative trends and in some cases no statistically significant trends. Non-linear relationship of rainfall to catchment stores (e.g., groundwater, soil moisture, aquifer, etc.) in some areas of the Sahel exist (see, e.g., Descroix et al., 2009; Séguis et al., 2004). In spite of decreasing rainfall in western Niger, Favreau et al. (2009), for example, reported a tremendous increase in water table, which they attributed to changes in land use pattern. These are some complicated and non-linear hydrological processes that characterise the region, which can possibly result from some other factors that may include: vegetation cover, soil type, depth to water table, greater infiltration, topography, amongst other factors. But in the key upstream and downstream areas of the Equatorial countries (e.g., DRC, Cameroon, and Gabon, etc.) that have strong seasonal rainfall (cf. Figs. 4b and e-f), there are locations with considerable declines in WGHM groundwater, suggesting long term hydrological droughts in the region (Fig. 9f).

\subsection{Impact of the Congo river on terrestrial water storage dynamics of the Congo basin}

Apart from being under-represented in the literature on African climate variability (e.g., Alsdorf et al., 2016; Todd and Washington, 2004), there is a prominent gap in our understanding of hydrological conditions in the Congo basin compared to other tropical continental river basins and regions in TWA (e.g., Niger, Volta basins, and West Africa at large) where some GRACE hydrological studies have been reported (see, e.g., Werth et al., 2017; Ndehedehe et al., 2016a, 2017a; Henry et al., 2011). Few GRACE studies, e.g., the pioneering work of Crowley et al. (2006) over the Congo basin and that of Lee et al. (2011) in the Congo basin cuvette have nonetheless, been reported. As the aforementioned studies did not study the impact of Congo river on GRACE-derived TWS, this section discusses the role of the Congo river on the water storage dynamics of the basin. The Congo river (has an approximate length of $4700-5100 \mathrm{~km}$ ) is the second largest river in Africa and drains one of the largest tropical forests of the world (Shahin, 2008). Given that low discharge values are observed between July and August, a period corresponding to low annual rainfall and 


$$
\text { with }
$$
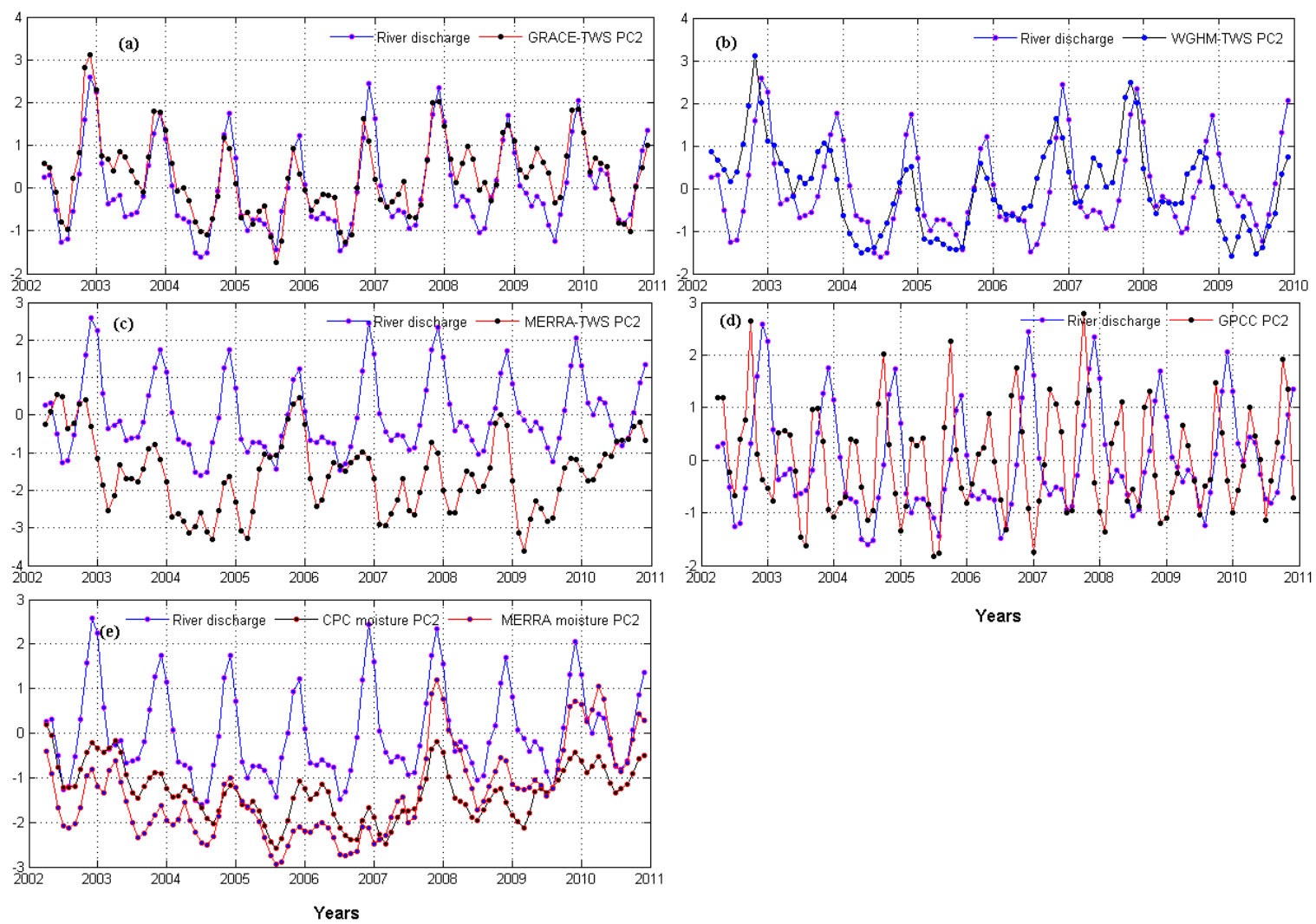

Figure 10: The relationship between the Congo river and TWS. The temporal patterns (PC2, Figs. 5, 6, and 7) of (a) GRACE-derived TWS, (b) WGHM-TWS, (c) MERRA-TWS, (d) GPCC-based precipitation, and (e) soil moisture (i.e., CPC and MERRA products) are compared with the standardised anomalies of river discharge at the Congo Kinshasa station for the common time period (2002 - 2010). All correlations are statistically significant at $95 \%$ confidence level.

charge anomalies showed the strongest association with the time series associated with the second EOF of GRACE-TWS (PC2, Fig. 7), indicating a statistically significant correlation of $0.86(\rho<0.05)$ compared to those of WGHM-TWS $(r=0.61, \rho<0.05)$, MERRA-TWS $(r=0.37)$, and GPCC-precipitation $(r=0.02)$ (Figs. 10a-d). But GPCC-precipitation (PC2, Fig. 5) is associated with river discharge anomalies during the same period at 2 months lag $(r=0.50, \rho<0.05)$ (Fig. 10d). The temporal patterns of soil moisture over the Congo basin (CPC and MERRA PC2, Fig. 6) showed moderate associations $(r=0.51$ and $r=0.50$ for CPC and MERRA products, respectively) with river discharge (Fig. 10e).

The singular spectral analysis of two leading components of river discharge, which were 
based on SVD decomposition of the lagged covariance matrices were also compared with GPCC-precipitation (PC2, Fig. 5), soil moisture (PC2, Fig. 6), and GRACE TWS (PC2, Fig. 7) modes over the Congo basin using regression. The annual (first spectral mode indicating $R^{2}=0.70$ with TWS) and the multi-annual (second spectral mode indicating $R^{2}=0.50$ with TWS) variations of river discharge, which accounted for total variabilities of $75 \%$ and $23 \%$, respectively, explained $70 \%$ and $50 \%$ of the variability in GRACE-TWS (Figs. 11a-b). These river discharge modes, however, showed no relationship with GPCC-rainfall (Figs. 11cd), but rather interestingly, similar to the earlier analysis, at two months lag time, maximum correlations were found ( $r=0.33$ and $r=0.64$, respectively). The association of soil moisture with the first spectral mode of river discharge (annual variations) are consistent as indicated earlier ( $r=0.50$ and $R^{2}=0.25$ for both CPC and MERRA soil moisture products) while the second spectral mode of river discharge (multi-annual variations) indicated correlations of $0.41\left(R^{2}=0.17\right)$ and $0.34\left(R^{2}=0.12\right)$ with CPC and MERRA soil moisture products, respectively (Figs. 11e-f). Hence, this evidence suggests that the multi-annual changes in
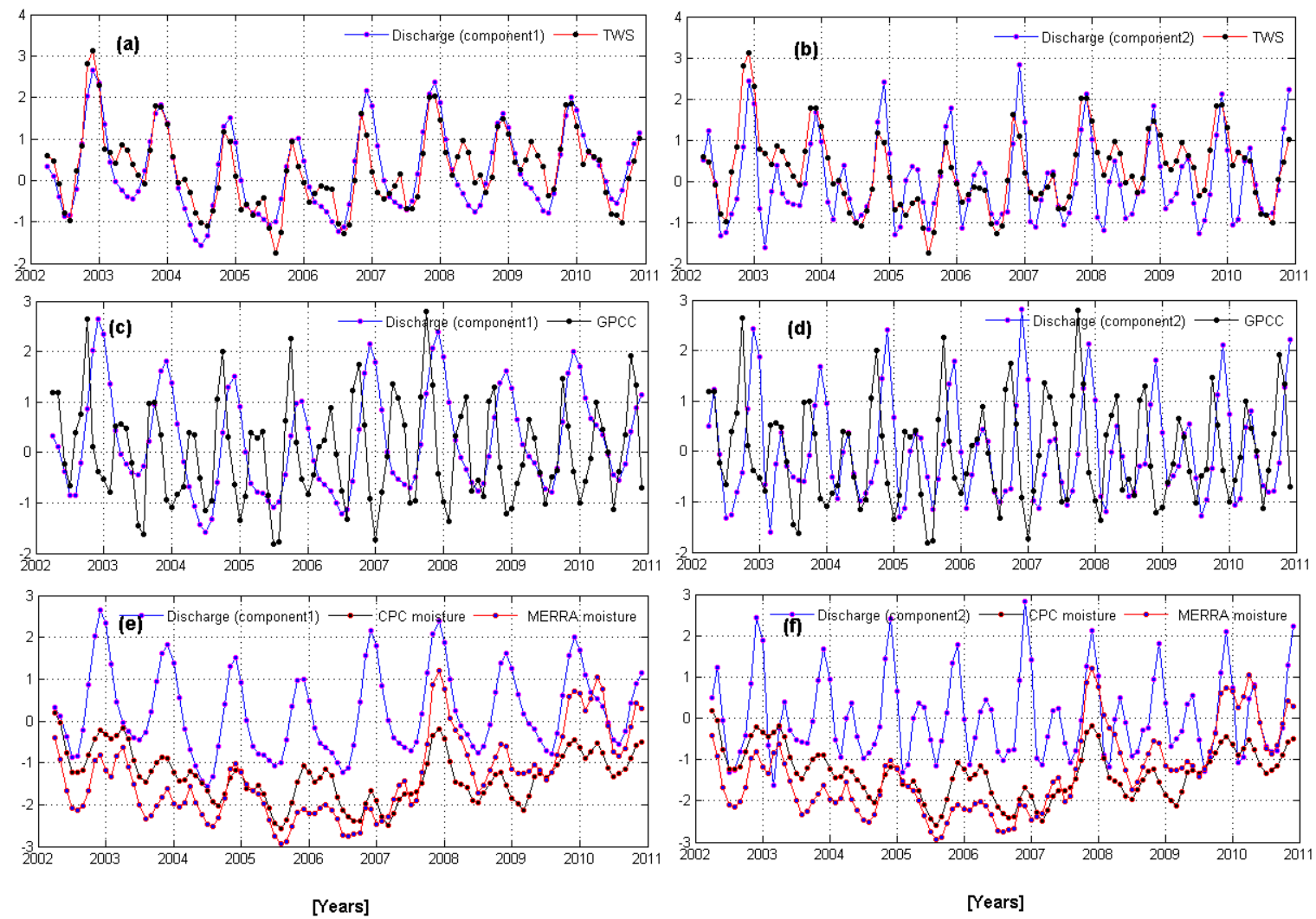

Figure 11: Singular spectral analysis of river discharge time series of the Congo basin. (a/c/e) The annual variations and (b/d/f) multi-annual variations of river discharge in the Congo basin are compared with GPCCbased precipitation (PC2, Fig. 5), soil moisture (i.e., CPC and MERRA PC2, Fig. 6), and GRACE-derived TWS (PC2, Fig. 7) over the Congo basin. The time series of river discharge are the reconstructed expansion coefficients.

land water storage (GRACE-derived TWS, PC2, 7) over the Congo basin is largely and prominently induced by its surface waters (river discharge), that is, in addition to the soil 
moisture variation previously discussed. WGHM-TWS also shows a better association with river discharge (Fig. 10b) compared to MERRA-TWS (Fig. 10c) perhaps due to the presence of groundwater and discharge in the WGHM data. The hydrological significance of rainfall in the land water storage dynamics is not ruled out as the central Congo receives high tropical rainfall of $1800-2400 \mathrm{~mm}$ annually with almost no dry season (Gupta, 2007). For example, between the early 2003 and 2005, Crowley et al. (2006) noted that precipitation contributed roughly three times the peak water storage after an unusual rainy season in the Congo basin. On the analysis of temporal variability in the water resources of TWA using historical stream flow data, Conway et al. (2009) argues that rainfall amongst other factors (e.g., human interventions) provides the dominant control on inter-annual and decadal variability in river flows. The aerial averaged GPCC precipitation over the Congo basin indicates a strong association $(r=0.70, \rho<0.05)$ with river discharge at one month lag. This simply reinforces the role of rainfall as a principal component in the variations of river discharge of the Congo basin, though this relationship (rainfall-river discharge) varies on decadal time scales as observed in West Africa by Conway et al. (2009).

But the flow regime of the Congo river is however, somewhat complex. Mostly because of its catchment characteristics, equatorial climate and the multiple sources of discharge from tributaries originating from the highlands and mountains of the East Africa Rift, Lake Tanganyika, Lake Mweru, even up to the Lualaba river, and the central Congo (see details in Shahin, 2008). Due to physiographic features, some of these rivers have complex drainage systems that affect their temporal stability and relationship with rainfall. Whereas this is true for the Congo basin as reported by Conway et al. (2009), they further reported a case study of weak relationship between outflows from Lake Victoria and basin rainfall, even during periods of stationary conditions. Such non-stationary behaviour between river discharge and rainfall evolutions exists in the Congo basin. Because of its climatological diversity and the impacts of physical mechanisms such as the Walker circulations, ENSO, and SST on rainfall variability (e.g., Farnsworth et al., 2011; Nicholson and Selato, 2000), the river discharge-rainfall relationship in the basin can only be more complicated. However, since technically, GRACE measures changes in the Earth's total integrated vertical column of water, the combined effect of multiple discharge sources (surface water) and heavy rainy seasons are major fluxes that will primarily drive the GRACE water column in the Congo basin.

Furthermore, Gupta (2007) reported on the seasonal flow regime, indicating that observed increase in river discharge at the Kinshasa station, occurs between April and June due to increased flow from the southern basin, thereby triggering a second discharge peak, different from the major first peaks that occurs between November and January. These two flow regimes in the basin, coincides with the semi-annual patterns in the temporal evolutions of 

driver of GRACE-TWS in the region. In summary, while the TWS of most countries in
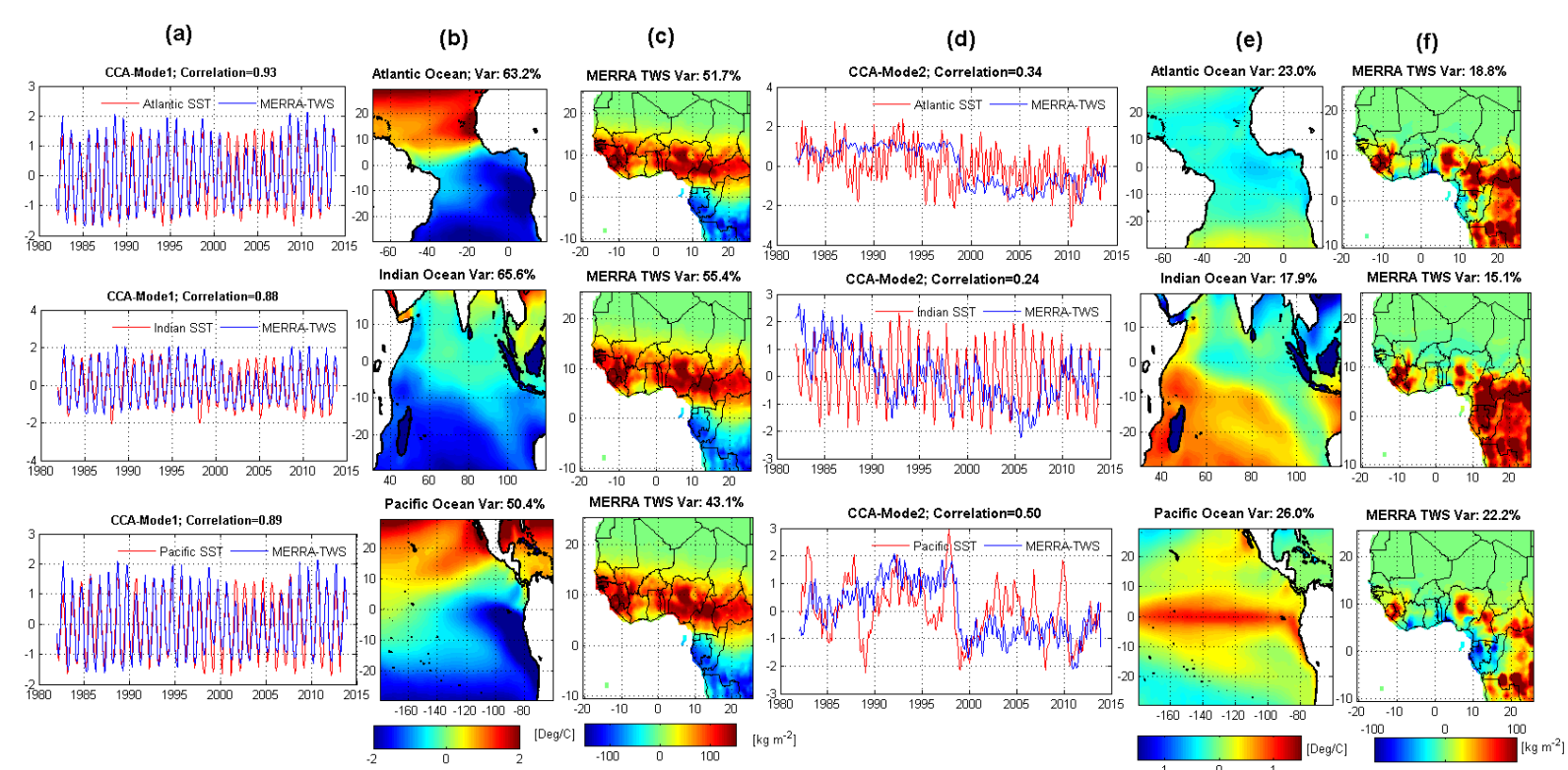

Figure 12: Leading canonical modes of SST (Atlantic, Indian and Pacific Oceans) and MERRA TWS (1982 - 2014). The canonical component time series of SST (predictors) and MERRA TWS (predictands) are in normalised units ( $a$ and d). The SST ( $b$ and e) and MERRA TWS ( $c$ and f) loadings have been adjusted to their original units (i.e., DegC and mm, respectively). Their variances (Var) explained in percentages are also indicated.

West Africa (e.g., Guinea, Nigeria, Mali, Liberia, Cameroon, etc.) are triggered by annual precipitation cycles induced by ocean circulations, altitude and physiographic features as reported previously (Ndehedehe et al., 2016a), the analyses in this study show that GRACEderived TWS over the Congo basin is however, largely determined and driven by changes in the river discharge of the Congo basin. In the next section, the impact of climate variability on the basin's water fluxes (TWS and river discharge) is discussed.

\subsection{TWS and links to sea surface temperature (SST)}

\subsubsection{Influence of global SST on long term MERRA-TWS (1982-2015)}

Large scale SST anomalies have been identified as significant components of observed variabilities in rainfall over tropical West Africa-TWA (e.g., Odekunle and Eludoyin, 2008; Farnsworth et al., 2011; Semazzi et al., 1988; Nicholson, 2013, and the references therein). Establishing the association between SST and TWS forms the physical basis of understanding the response of land water storage to inter-annual changes in global climate. The focus in this section is to examine the links between TWS over TWA and global climates based on CCA. Prior to the implementation of canonical correlation analysis (CCA), the 
Table 2: Regression results $\left(R^{2}\right)$ of temporal evolutions of SST (PC1 and PC2) over the three oceans (Atlantic, Indian, and Pacific) with those of TWS MERRA (1982 - 2014) and GRACE (2002 - 2014). Relationships are significant at the $95 \%$ significant level for $R^{2}$ in bold.

\begin{tabular}{llllllll}
\hline Data & PCs & \multicolumn{3}{c}{ Atlantic Ocean } & \multicolumn{2}{l}{ Indian Ocean } & \multicolumn{2}{l}{ Pacific Ocean } \\
\hline & Temporal & PC1 & PC2 & PC1 & PC2 & PC1 & PC2 \\
\hline Merra TWS & PC1/PC2 & $\mathbf{0 . 5 6}$ & 0.03 & $\mathbf{0 . 4 4}$ & 0.008 & $\mathbf{0 . 5 3}$ & 0.006 \\
GRACE-TWS & PC1/PC2 & $\mathbf{0 . 7 2}$ & $\mathbf{0 . 2 1}$ & $\mathbf{0 . 4 8}$ & 0.00 & $\mathbf{0 . 6 6}$ & 0.05 \\
\hline
\end{tabular}

pre-orthogonalisation results (i.e., the first and the second modes of SST and TWS) were compared using regression. From the regression results summarised in Table 2, the leading temporal variations of TWS (PC1), especially GRACE show strong relationship with those of SST anomalies in the three Oceans. The temporal components of Atlantic and Pacific SST in these leading modes show strong association with MERRA TWS compared to the Indian Ocean (Table 2). These relationships are reliable indicators of SST anomalies as prominent drivers of TWS in the region. But in the CCA results, significant associations are found in the two retained canonical modes. The CCA maps ( $g$-map or the predictor map and $h$-map or the predictand map) and their temporal series, i.e., the canonical variables for the first and second modes of MERRA-TWS/SST and GRACE-TWS/SST are indicated in Figs. 12 and 13, respectively. The principal loading patterns (CCA spatial patterns or maps) associated with the temporal series (i.e., $u$ and $v$ ) in the first canonical modes (Figs. 12a-c) show that strong negative and positive SST anomalies in the three oceans represent strong potential predictors for the dominant mode of MERRA-TWS over TWA. Their temporal series (Fig. 12a) are highly correlated (Table 3) and indicate the inter-annual variations in the observed amplitudes of the predictor loading patterns (Fig. 12b). Two well known features are observed in the heterogenous patterns (except for the Indian Ocean) of the first CCA modes of the predictor maps. Firstly, the warming of the northern ocean indicated by strong positive canonical loadings and cooling of the south-eastern Oceans (Fig. 12b). Secondly, these patterns are analogous to strong positive canonical loadings in West Africa and strong negative loadings in Equatorial countries (Figs. 12b). These predictor loadings, which essentially show an inter-hemispheric dipole configurations (except for the Indian Ocean), strongly influences the variability of the predictand (Fig. 12c). Meanwhile, the large scale coherent negative canonical loadings over the southern Indian Ocean exhibited by the first CCA mode of SST field (Fig. 12b) suggest the predominant control of this Ocean on the annual variability of TWS in the region. When instigated by other physical mechanisms (e.g., ENSO), or sometimes in conjunction with the Atlantic Ocean, the Indian Ocean plays a complementary role on inter-annual rainfall variability in TWA. For example, teeming up with an anomalously warm eastern tropical Atlantic SST, an unusually warm Indian Ocean SST is known to affect moisture transports, causing reduced rainfall and drought in the Sahel 
Table 3: Results of canonical correlations of SST (CCA-1 and CCA-2) over the three oceans (Atlantic, Indian, and Pacific) with those of MERRA TWS (1982 - 2014) and GRACE-TWS (2002 - 2014). Relationships are significant at the $95 \%$ significant level for all canonical correlation values.

\begin{tabular}{llllllll}
\hline Data & Vectors & \multicolumn{2}{c}{ Atlantic Ocean } & \multicolumn{2}{c}{ Indian Ocean } & \multicolumn{2}{c}{ Pacific Ocean } \\
\hline & Temporal series & CCA-1 & CCA-2 & CCA-1 & CCA-2 & CCA-1 & CCA-2 \\
\hline Merra TWS & CCA-1/CCA-2 & $\mathbf{0 . 9 3}$ & $\mathbf{0 . 3 4}$ & $\mathbf{0 . 8 8}$ & $\mathbf{0 . 2 4}$ & $\mathbf{0 . 8 9}$ & $\mathbf{0 . 5 0}$ \\
GRACE-TWS & CCA-1/CCA-2 & $\mathbf{0 . 9 6}$ & $\mathbf{0 . 6 1}$ & $\mathbf{0 . 9 6}$ & $\mathbf{0 . 6 3}$ & $\mathbf{0 . 9 5}$ & $\mathbf{0 . 6 5}$ \\
\hline
\end{tabular}

region of TWA (Bader and Latif, 2011; Giannini et al., 2003). In Africa, some studies (e.g., Farnsworth et al., 2011; Nicholson and Selato, 2000) have further confirmed that SSTs in the Indian and Atlantic Oceans influence rainfall variability. Whereas the impact of SST anomalies of these two Oceans is an important consideration for an ENSO event, their actual connection is undetermined and inconclusive (Farnsworth et al., 2011). However, strong changes in regional precipitation resulting from the perturbations of these Oceans have direct impacts on the variations in land water storage over TWA. Considering the total variabilities explained by the first and second canonical modes (65\% and $17.9 \%$, respectively) of SST over the Indian Ocean and their corresponding correlations (Table 3), this study confirms that the Indian Ocean are also predictors of variabilities in TWS over the region.

In the second canonical modes of SST and MERRA-TWS, the temporal components of pacific SST and MERRA-TWS are relatively better correlated, indicating a correlation of $0.50(\rho<0.05)$ (Table 3 for Pacific Ocean) compared to other canonical vectors (Figs. 12d). Given the significance of the Pacific Ocean as a very popular oceanic hot spot that plays key roles in El-Niño and La-Niña cycles (e.g., Koster et al., 2004; Trenberth, 1997), the temporal component of the second CCA mode of Pacific SST anomalies, accounting for $26.0 \%$ of the total variability (Fig. 12e) is an ENSO-related mode. This is because the temporal component (Pacific SST) of this CCA mode indicated a correlation of $0.90(\rho<0.05)$ with the ENSO index, suggesting the prominent role of ENSO in the inter-annual variations of MERRATWS in the tropical areas of TWA (Fig. 12f), especially the upstream and downstream areas of the Congo basin. Since rainfall patterns over Africa are strongly affected by a number of global climate modes as is the case in many parts of the world, the coupled effect of the ENSO phenomenon on a large part of the variability in MERRA TWS over TWA as shown in Figs. 12d-f (Pacific SST) would be expected. When this is juxtaposed with the significant correlation between rainfall anomalies in TWA and tropical Pacific SST reported e.g., by Semazzi et al. (1988), it is here argued that the equatorial Pacific represents a significant and probably one of the most relevant oceanic hot spot that play key roles in strong hydrological changes in TWA.

The second CCA modes of Atlantic and Indian SST anomalies (Figs. 12d-f), however, are weakly associated with MERRA-TWS (0.34 and 0.24, respectively). Furthermore, Atlantic 
Multi Decadal Oscillation (AMO) is modestly associated with the Atlantic SST in the second CCA mode $(r=-0.50, \rho<0.05)$ (Fig. $12 \mathrm{~d}$ ), and may also represent a significant climate mode from the Atlantic Ocean that somewhat influences TWS in TWA. A study on global trends and variability in soil moisture and drought characteristics by Sheffield and Wood (2008) suggests that apart from ENSO, the variability in AMO accounts for some of the inter-annual and decadal variabilities in soil moisture and drought characteristics in West Africa and many other regions of the world. Although such influence may be different when TWS is considered, the CCA results show that the long term MERRA-TWS is able to detect prominent indices of climate variability (e.g., ENSO, AMO, etc.) that impacts on the climate system of TWA. This would be consistent with some pioneering studies (e.g., Ndehedehe et al., 2017b; Boening et al., 2012; Phillips et al., 2012) that have shown how teleconnection patterns around the globe are associated with changes in global mean sea level and continental water storage. As part of the numerical results obtained in this study, strong warming in

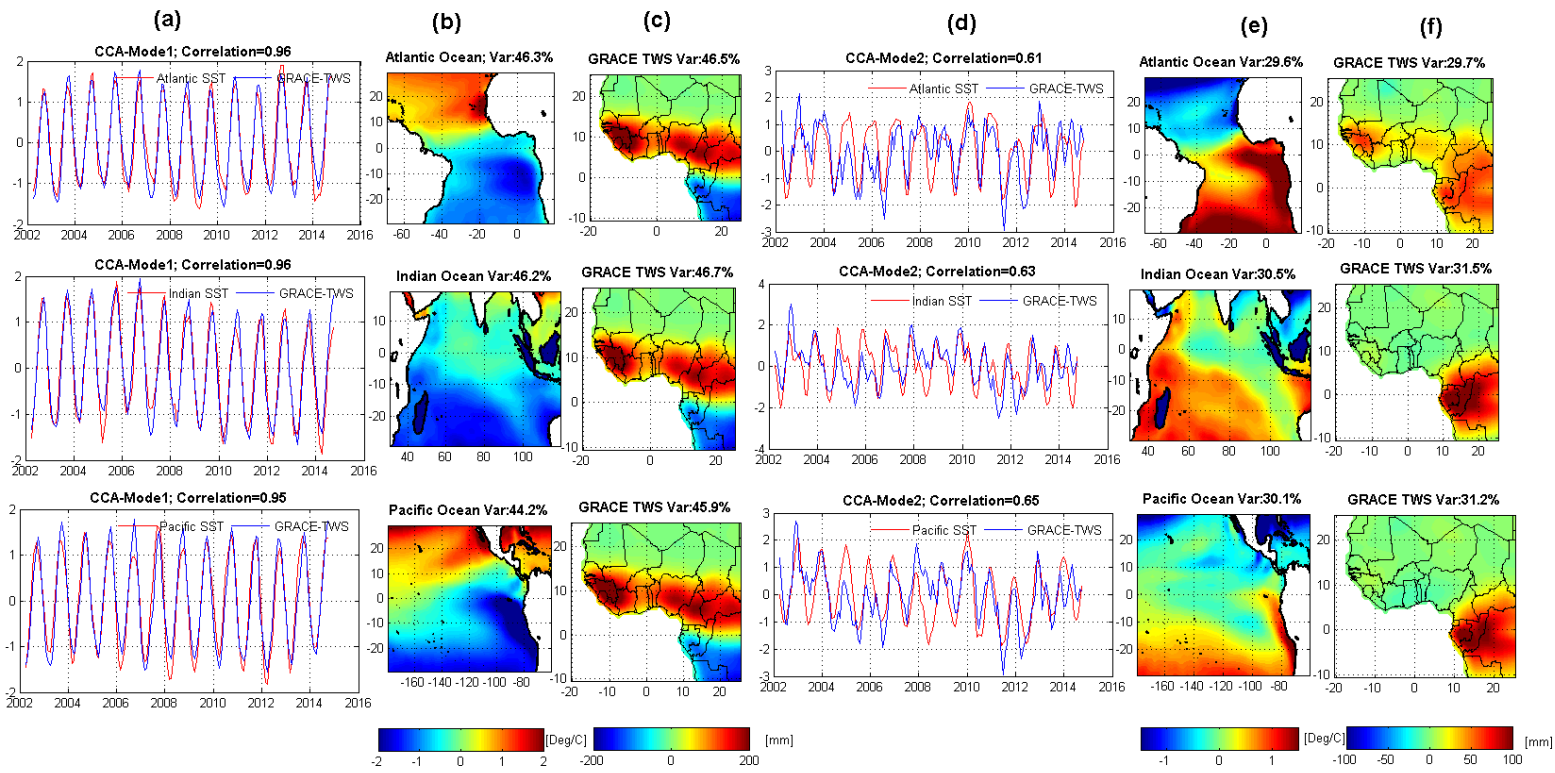

Figure 13: Leading canonical modes of SST (Atlantic, Indian and Pacific Oceans) and GRACE TWS (2002 - 2014). The canonical component time series of SST (predictors) and GRACE TWS (predictands) are in normalised units ( $a$ and d). The SST ( $b$ and e) and GRACE TWS (c and f) loadings have been adjusted to their original units (i.e., DegC and $\mathrm{mm}$, respectively). Their variances (Var) explained in percentages are also indicated.

most parts of the Oceans except in the Pacific where some areas indicate both cooling and a considerable warming was observed. Whereas this warming of the global oceans coincides with observed negative trends in TWS and soil moisture in much of TWA (Figs. 9b-e), it also suggests the interplay of the three Oceans in modulating moisture transports across the region. For example, the weight of evidence have shown that changes in SST anomalies in the north tropical Atlantic, apart from modulating the Pacific climate variability, can influence the predictability and variability of ENSO and trigger its events (see, Ham et al., 2013, and 
the references therein). Consequently, the warming of the tropical Atlantic Ocean during the $1982-2014$ period (not shown) maybe very significant to the observed relationships of ENSO and AMO with TWS, confirming their roles in the region.

\subsubsection{Relationship of SST with GRACE-TWS during the 2002-2014 period}

The CCA diagnostics also show that the dominant modes of SST evolutions of the three Oceans (Atlantic, Indian, and Pacific) have strong influence on annual GRACE-TWS variations (Figs. 13a-c) as the canonical correlations (Table 3) for the first and second CCA modes are relatively high and statistically significant $(\rho<0.05)$. The temporal components of SST from all Oceans in the second CCA modes are reasonably or well correlated with GRACE-TWS (Fig. 13d), indicating that all oceans play significant roles in the observed GRACE-TWS changes of the Congo basin (Figs. 13e-f). Apart from the Congo basin, GRACE-TWS in Guinea is potentially predictable from the inter-hemispheric dipole configurations of the strong SST patterns in the Atlantic Ocean as can be seen in the second CCA mode (Figs. 13d-f). The annual and bimodal features reflected in the inter-annual variations of rainfall (cf. Fig. 5) over TWA are propagated in the CCA of the two fields-SST and GRACE-TWS (Figs. 13a and d) and implies a strong coupling between the two. Large coherent positive loadings observed in the predictor maps (i.e., $g$ ) of the southern and eastern parts of all Oceans in the CCA modes (Fig. 13e) are in association with strong positive canonical loadings in the predictand maps (i.e., $h$ ) observed over the Congo basin (Fig. 13f). These are useful CCA diagnostics, which may provide some important explanations on observed physical mechanisms that help relates the SST fields to those of GRACE-TWS. For instance, in the last half of the 20th century, the warming of the South and North Atlantic Oceans have contributed to drying conditions in the region (e.g., Nicholson, 2013; Giannini et al., 2013). Although changes in the Indian Ocean SST have also been identified as inducing dry conditions in the Sahel region as highlighted earlier, such impacts as reported by Giannini et al. (2003), are usually facilitated by an occasionally warmer-than-average SST of the eastern Atlantic Ocean.

Whereas it is agreed that SST in the equatorial Atlantic favour convection in the Guinea Coast countries (see, e.g., Odekunle and Eludoyin, 2008; Nicholson and Webster, 2007), Aguilar et al. (2009) observed over Central Africa (much of the Congo basin) a decrease in heavy (total) precipitation over the last half century. A similar change in the climate patterns of the region has again emerged in a more recent study by Hua et al. (2016). They observed drying trends in equatorial Africa and suggests that it is essentially modulated by SSTs and the regional/global atmospheric circulation patterns. As one of the major convective regions of the world, which during the transition seasons, dominates global tropical rainfall (Washington et al., 2013), the Congo basin's rainfall climatology is strongly influenced by SST teleconnection patterns (notably ENSO and the Indian Ocean dipole oscillation) and 
Table 4: Correlations results of SST canonical components (CCA-1 and CCA-2) over the Atlantic, Indian, and Pacific Oceans (Fig. 13) with observed river discharge anomalies during the same period (2002 - 2010). Correlations are statistically significant $(\alpha=0.05)$ for all values in bold. Those marked with asterisks $(*)$ are not statistically significant.

\begin{tabular}{lllllll}
\hline Data & Vectors & \multicolumn{2}{c}{ Atlantic Ocean } & \multicolumn{2}{c}{ Indian Ocean } & \multicolumn{2}{c}{ Pacific Ocean } \\
\hline Temporal series & CCA-1 & CCA-2 & CCA-1 & CCA-2 & CCA-1 & CCA-2 \\
\hline River discharge & $* 0.09$ & $\mathbf{0 . 7 6}$ & $*_{0.07}$ & $\mathbf{0 . 7 7}$ & $*_{0.13}$ & $\mathbf{0 . 7 4}$ \\
GPCC-rainfall & $\mathbf{0 . 2 2}$ & $\mathbf{0 . 6 0}$ & $\mathbf{0 . 2 0}$ & $\mathbf{0 . 6 3}$ & $\mathbf{0 . 2 0}$ & $\mathbf{0 . 4 2}$ \\
\hline
\end{tabular}

provides more challenges in the set up of attribution studies (see, Otto et al., 2013). Considering that SST, atmospheric circulation features, synoptic and mesoscale convective systems regulate rainfall conditions in the Congo basin (Equatorial Africa), such influence play key role on hydrological processes (considerable changes in TWS) of the region at seasonal and annual time scales. It is suggested here that the relational stability (the somewhat consistent association between the canonical variate) observed in the temporal series (Fig. 13d) of the second CCA mode (Table 3) and the evolutionary developments of their corresponding predictor and predictand maps (Figs. 13e-f) would be logical indications that these parts of the Oceans have considerable influence on the regional variability of TWS in TWA. Specifically, the SST of all southern Oceans modulate GRACE-TWS changes in the Congo basin by directly influencing the tropical rain belt and the inter-tropical convergence zone (ITCZ). A plethora of case studies in Farnsworth et al. (2011) have reported on the observed relationships between large scale SST anomalies and rainfall variability in the region (including the Congo basin), confirming that SST variations and land-surface gradients modulate rainfall in the Congo basin area by directly influencing the strength and loci of the tropospheric jets. It is also noted that the temporal component of Atlantic SST in the second CCA mode (Fig. 13d) associated with the heterogenous patterns of the predictor map (Fig. 13e) covaries well with the Atlantic Meridional Mode-AMM index $(r=0.50, \rho<0.05)$, re-emphasising the Atlantic SST as a driver of GRACE-TWS variability.

Unlike MERRA TWS, the short time series of GRACE-TWS makes its difficult to identify any low frequency climate oscillation in the main portion of the CCA procedure that is associated with its changes. The AMO, for instance, is a 'multi-decadal' oscillation with a large spectral energy density at periods spanning more than two decades compared to ENSO, which has a large energy between $2-5$ years, with positive and negative phases having large asymmetric amplitude variations. Although the ENSO oscillations were not isolated in the main portion of the CCA procedure (GRACE Vs SST), considerable strong and significant relationship exist between the SST of the three Oceans and GRACE-TWS (Table 3) and could be helpful to forecast the development of several types of ENSO episodes (Ham et al., 2013) and other indices of climate variability that are known to have broad 
impacts on rainfall variance in the region. The coherent relationship of SST anomalies in the second CCA mode with GRACE-TWS index in the Congo basin area (Figs. 13d-f) is sufficient to suggest that the scale of oceanic influence in the basin is global. It is interesting that the temporal components of SST in the CCA output presented in Fig. 13 are also related to inter-annual variability of river discharge and precipitation in the Congo basin. Their correlation results summarised in Table 4 suggest that river discharge of the Congo basin is more dynamically coupled to the second CCA mode of SST over the three oceans (Figs. 13d-f). Although rainfall also show a direct association as would be expected, river discharge indicated relatively stronger correlation with the temporal series of SST from all oceans in the second CCA mode (Table 4). This would be consistent with the discussion in Section 4.2, where river discharge is said to provide the dominant control on GRACETWS in the Congo basin. The Congo basin's river discharge indicates consistent and strong positive relationship with the SST anomalies of the three oceans and is consistent with other studies that reported similar positive association between rainfall in the Congo basin and SST of the Atlantic and Indian Oceans (e.g., Farnsworth et al., 2011; Todd and Washington, 2004). Considering that SST from the three oceans explain large parts of the variability in the Congo river discharge (Table 4), which shows considerable association with GRACEhydrological signal, then changes in SST will impact on the hydrological variability of the Congo basin. With GRACE data being able to identify multi-annual changes in the river discharge of the Congo basin (Figs. 10a and 11a), essentially, it is emerging as a stronger tool for studies of hydrological processes, especially in the light of its recent agreement with altimeter observations over the Caspian Sea (see, Chen et al., 2017).

\section{Conclusion}

Long term hydrological changes $(1980-2015)$ based on a suite of model and global reanalysis data over tropical West Africa (TWA) and their links to SST anomalies were studied using several multivariate techniques and Man-Kendall's statistics. On the one hand, GRACE data was employed to examine key hydrological metrics and the impacts of ocean perturbations on the terrestrial hydrology of TWA. Model and reanalysis data on the other hand, were employed to help complement the short time series of GRACE in assessing the hydrological properties of TWA and to identify global teleconnection patterns and climate oscillations that may impact on the temporal variations of land water storage and hydrometeorological conditions. The results are summarised as follows;

(1) The broad agreement across models and reanalysis data on declines in land water storage (TWS, soil moisture, and groundwater) in the Congo basin confirms a statistically significant $(\rho<0.05)$ long term drying in the region and coincides with warming of the land surface and the surrounding oceans. Some areas in West Africa and the Congo 
basin however, show statistically significant positive trends in the model groundwater. Some of these positive trends (model groundwater) are somewhat inconsistent with those of rainfall, soil moisture, and TWS in some areas, probably due to land surface conditions and complex hydrological processes. Meanwhile, the Sahel show some wetting trends in rainfall, soil moisture, and TWS during the period. This generally aligns with the ongoing narratives of rainfall recovery in the Sahel region. The observed trends in these dataset should be interpreted with caution given that the output of these models maybe sensitive to the forcing dataset that drives them and due to potential uncertainties that maybe associated with them.

(2) GRACE hydrological signal over the Congo basin is strongly associated with the multiannual changes in the Congo river discharge $(r=0.86, \rho<0.05)$. The relationship between the two leading components of river discharge obtained from singular spectral analysis and the temporal evolutions of GRACE-derived TWS over the Congo basin (i.e., $R^{2}=0.70$ and 0.50 for the first and second spectral components, respectively), confirm that the Congo river discharge remains a prominent hydrological indicator that contributes significantly to observed variations in GRACE-derived TWS. In addition, it shows a considerable association with SST anomalies of all the three southern Oceans (Atlantic, Indian, and Pacific). The declines in soil moisture $(\backsim-45.9 \pm 8.1 \mathrm{~mm} / \mathrm{yr}$, $\rho<0.05)$ in the basin coincided with those of GRACE-TWS $(\backsim-78.4 \pm 20.3 \mathrm{~mm} / \mathrm{yr}$, $\rho<0.05)$ during the $2003-2006$ period, also confirming the significant role of interannual changes in soil moisture to the observed variations in GRACE-TWS. In the light of its recent agreement with other large scale satellite geodetic missions, and the ability to resolve strong signals of water storage variations over surface waters in smaller basins, GRACE gravimetry emerges as a stronger 'tool in the box' for studies of hydrological changes and monitoring the impacts of climate variability in the data deficient African region.

(3) The CCA diagnostics showed that the scale of oceanic influence on MERRA and GRACE TWS over TWA is global. ENSO related equatorial Pacific SST fluctuations was a major index of climate variability identified in the main portion of the CCA procedure that showed a considerable association with long term MERRA data over TWA. Variabilities in Atlantic Meridional Mode and Atlantic Multi-decadal Oscillation were also found to be modestly associated with the canonical components of Atlantic SST. These climate oscillations indicated statistically significant $(\rho<0.05)$ association with TWS, re-emphasising the role of Atlantic SST variability in the region. It is obvious from the study that the data deficient sub regions of Africa can benefit from the applications of GRACE gravimetry and reanalysis data to monitor the impacts of climate variability on its terrestrial hydrology. 
(4) Over TWA, the leading modes (annual amplitudes) of long term variations in rainfall, soil moisture, and TWS data were found over West African countries (located between latitudes $5^{\circ} \mathrm{N}$ and $15^{\circ} \mathrm{N}$ ) and some countries of the Congo basin while Guinea, Liberia, Sierra Leone, and southern Nigeria have the strongest variability in model groundwater. These annual amplitudes generally show linear and considerable relationship with SST anomalies from the surrounding oceans. 


\section{Acknowledgments}

1060

Christopher E. Ndehedehe and Nathan O. Agutu are grateful to Curtin University, Perth,

Western Australia for providing the funding that supported them during the period this study was undertaken. The Authors are grateful to CSR, NASA, NOAA, and GRDC for the data used in this study. They are also grateful to Center for Environment Systems Research for the WaterGap model data and the two anonymous reviewers for their valuable comments. 


\section{References}

Aguilar, E., Aziz Barry, A., Brunet, M., Ekang, L., Fernandes, A., Massoukina, M., Mbah, J., Mhanda, A., do Nascimento, D. J., Peterson, T. C., Thamba Umba, O., Tomou, M., and Zhang, X. (2009). Changes in temperature and precipitation extremes in western central Africa, Guinea Conakry, and Zimbabwe, 19552006. Journal of Geophysical Research: Atmospheres, 114(D2):D02115. doi:10.1029/2008JD011010.

Agutu, N., Awange, J., Zerihun, A., Ndehedehe, C., Kuhn, M., and Fukuda, Y. (2017). Assessing multi-satellite remote sensing, reanalysis, and land surface models' products in characterizing agricultural drought in East Africa. Remote Sensing of Environment, 194(0):287-302. doi:10.1016/j.rse.2017.03.041.

Ahmed, M., Sultan, M., J.Wahr, and Yan, E. (2014). The use of GRACE data to monitor natural and anthropogenic induced variations in water availability across Africa. Earth Science Reviews, 136:289-300. doi:10.1016/j.earscirev.2014.05.009.

Alsdorf, D., Beighley, E., Laraque, A., Lee, H., Tshimanga, R., O'Loughlin, F., Mah, G., Dinga, B., Moukandi, G., and Spencer, R. G. M. (2016). Opportunities for hydrologic research in the congo basin. Reviews of Geophysics, 54(2):378-409. doi:10.1002/2016RG000517.

Alsdorf, D. E. and Lettenmaier, D. P. (2003). Tracking fresh water from space. Science, 301(5639):1491-1494. doi:10.1126/science.1089802.

Andam-Akorful, S., Ferreira, V., Ndehedehe, C. E., and Quaye-Ballard, J. (2017). An investigation into the freshwater variability in West Africa during $1979-2010$. International Journal of Climatology, 37(S1):333-349. doi:10.1002/joc.5006.

Asefi-Najafabady, S. and Saatchi, S. (2013). Response of African humid tropical forests to recent rainfall anomalies. Transactions of the Royal Society, 368:20120306. doi:10.1098/rstb.2012.0306.

Bader, J. and Latif, M. (2011). The 1983 drought in the West Sahel: A case study. Climate Dynamics, 36(3-4):463-472. doi:10.1007/s00382-009-0700-y.

Barnett, T. P. and Preisendorfer, R. (1987). Origins and levels of monthly and seasonal forecast skill for United States surface air temperatures determined by canonical correlation analysis. Monthly Weather Review, 115(9):1825-1850. doi:10.1175/15200493(1987)115;1825:OALOMA ¿2.0.CO;2.

Bekoe, E. O. and Logah, F. Y. (2013). The impact of droughts and climate change on electricity generation in Ghana. Environmental Sciences, 1(1):13-24. 
Boening, C., Willis, J. K., Landerer, F. W., Nerem, R. S., and Fasullo, J. (2012). The 2011 La Nia: So strong, the oceans fell. Geophysical Research Letters, 39(19):L19602. doi:10.1029/2012GL053055.

Boone, A., Decharme, B., Guichard, F., Rosnay, P. D., Balsamo, G., Belaars, A., Chopin, F., Orgeval, T., Polcher, J., Delire, C., Ducharne, A., Gascoin, S., Grippa, M., Jarlan, L., Kergoat, L., Mougin, E., Gusev, Y., Nasonova, O., Harris, P., Taylor, C., Norgaard, A., Sandholt, I., Ottle, C., Poccard-Leclercq, I., Saux-Picart, S., and Xue, Y. (2009). The AMMA Land Surface Model Intercomparison Project (ALMIP). Bulletin of American Meteorological Society, 90(12):1865-1880. doi:10.1175/2009BAMS27/86.1.

Boschetti, M., Nutini, F., Brivio, P. A., Bartholom, E., Stroppiana, D., and Hoscilo, A. (2013). Identification of environmental anomaly hot spots in West Africa from time series of NDVI and rainfall. ISPRS Journal of Photogrammetry and Remote Sensing, 78:26 - 40. doi:10.1016/j.isprsjprs.2013.01.003.

Chen, J. L., Wilson, C. R., Tapley, B. D., Save, H., and Cretaux, J.-F. (2017). Long-term and seasonal Caspian Sea level change from satellite gravity and altimeter measurements. Journal of Geophysical Research: Solid Earth, 122(3):2274-2290. doi:10.1002/2016JB013595.

Conway, D., Persechino, A., Ardoin-Bardin, S., Hamandawana, H., Dieulin, C., and Mahé, G. (2009). Rainfall and water resources variability in Sub-Saharan Africa during the twentieth century. Journal of Hydrometeorology, 10(1):41-59. doi:10.1175/2008JHM1004.1.

Crowley, J. W., Mitrovica, J. X., Bailey, R. C., Tamisiea, M. E., and Davis, J. L. (2006). Land water storage within the Congo Basin inferred from GRACE satellite gravity data. Geophysical Research Letters, 33(19):L19402. doi:10.1029/2006GL027070.

Dardel, C., Kergoat, L., Hiernaux, P., Mougin, E., Grippa, M., and Tucker, C. (2014). Re-greening Sahel: 30 years of remote sensing data and field observations (Mali, Niger). Remote Sensing of Environment, 140:350 - 364. doi:10.1016/j.rse.2013.09.011.

Descroix, L., Mahé, G., Lebel, T., Favreau, G., Galle, S., Gautier, E., Olivry, J.-C., Albergel, J., Amogu, O., Cappelaere, B., Dessouassi, R., Diedhiou, A., Breton, E. L., Mamadou, I., and Sighomnou, D. (2009). Spatio-temporal variability of hydrological regimes around the boundaries between Sahelian and Sudanian areas of West Africa: A synthesis. Journal of Hydrology, 375(12):90-102. doi:10.1016/j.jhydrol.2008.12.012.

Diaz, H. F., Hoerling, M. P., and Eischeid, J. K. (2001). Enso variability, teleconnections and climate change. International Journal of Climatology, 21(15):1845-1862. doi:10.1002/joc.631. 
Dimri, A., Yasunari, T., Wiltshire, A., Kumar, P., Mathison, C., Ridley, J., and Jacob, D. (2013). Application of regional climate models to the Indian winter monsoon over the western Himalayas. Science of The Total Environment, 468-469, Supplement:S36 - S47. doi:10.1016/j.scitotenv.2013.01.040.

Döll, P., Müller Schmied, H., Schuh, C., Portmann, F. T., and Eicker, A. (2014a). Globalscale assessment of groundwater depletion and related groundwater abstractions: Combining hydrological modeling with information from well observations and GRACE satellites. Water Resources Research, 50(7):5698-5720.

Döll, P., Müller Schmied, H., Schuh, C., Portmann, F. T., and Eicker, A. (2014b). Globalscale assessment of groundwater depletion and related groundwater abstractions: Combining hydrological modeling with information from well observations and GRACE satellites. Water Resources Research, 50(7):5698-5720.

Douville, H., Conil, S., Tyteca, S., and Voldoire, A. (2007). Soil moisture memory and West African monsoon predictability: artefact or reality? Climate Dynamics, 28(7):723-742. doi:10.1007/s00382-006-0207-8.

Enfield, D. and Mestas-Nuñez, A. (1999). Multiscale variabilities in global sea surface temperatures and their relationships with tropospheric climate patterns. Journal of Climate, 12(9):2719-2733. doi:10.1175/1520-0442(1999)012¡2719:MVIGSS¿2.0.CO;2.

Erfanian, A., Wang, G., Yu, M., and Anyah, R. (2016). Multimodel ensemble simulations of present and future climates over West Africa: impacts of vegetation dynamics. Journal of Advances in Modeling Earth Systems, 8. doi:10.1002/2016MS000660.

Fall, S., Semazzi, F. H. M., Niyogi, D. D. S., Anyah, R. O., and Bowden, J. (2006). The spatiotemporal climate variability over Senegal and its relationship to global climate. International Journal of Climatology, 26(14):2057-2076. doi:10.1002/joc.1355.

Fan, Y. and Dool, H. V. (2004). Climate prediction center global monthly soil moisture data set at $0.5^{\circ}$ resolution for 1948 to present. Journal Of Geophysical Research, 109:D10102. doi:10.1029/2003JD004345.

Farnsworth, A., White, E., Williams, C. J., Black, E., and Kniveton, D. R. (2011). Understanding the Large Scale Driving Mechanisms of Rainfall Variability over Central Africa, In African Climate and Climate Change: Physical, Social and Political Perspectives, pages 101-122. Springer Netherlands, Dordrecht. doi:10.1007/978-90-481-3842-5_5.

Favreau, G., Cappelaere, B., Massuel, S., Leblanc, M., Boucher, M., Boulain, N., and Leduc, C. (2009). Land clearing, climate variability, and water resources in- 
crease in semiarid southwest Niger: a review. Water Resources Research, 45:W00A16. doi:10.1029/2007WR006785.

Fontaine, B. and Bigot, S. (1993). West African rainfall deficits and sea surface temperatures. International Journal Of Climatology, 13(3):271-285. doi:10.1002/joc.3370130304.

Funk, C., Peterson, P., Landsfeld, M., Pedreros, D., Verdin, J., Shukla, S., Husak, G., Rowland, J., Harrison, L., Hoell, A., and Michaelsen, J. (2015). The climate hazards infrared precipitation with stationsa new environmental record for monitoring extremes. Scientific Data, 2:150066. doi:10.1038/sdata.2015.66.

Ghil, M., Allen, M. R., Dettinger, M. D., Ide, K., Kondrashov, D., Mann, M. E., Robertson, A. W., Saunders, A., Tian, Y., Varadi, F., and Yiou, P. (2002). Advanced spectral methods for climatic time series. Reviews of Geophysics, 40(1):3-1-3-41. doi:10.1029/2000RG000092.

Giannini, A., Biasutti, M., Held, I. M., and Sobel, A. H. (2008). A global perspective on African climate. Climate Change, 90(7):359-383. doi:10.1007/s10584-008-9396-y.

Giannini, A., Salack, S., Lodoun, T., Ali, A., Gaye, A., and Ndiaye, O. (2013). A unifying view of climate change in the Sahel linking intra-seasonal, interannual and longer time scales. Environmental Research Letters, 8:1-8. doi:10.1088/1748-9326/8/2/024010.

Giannini, A., Saravanan, R., and Chang, P. (2003). Oceanic forcing of Sahel rainfall on interannual to decadal time scales. Science, 302(5647):1027-1030. doi:10.1126/science.1089357.

Glahn, H. R. (1968). Canonical correlation and its relationship to discriminant analysis and multiple regression. Journal of the Atmospheric Sciences, 25(1):23-31. doi:10.1175/15200469(1968)025;0023:CCAIRT¿2.0.CO;2.

Graham, N. E., Michaelsen, J., and Barnett, T. P. (1987). An investigation of the el niosouthern oscillation cycle with statistical models: 1. predictor field characteristics. Journal of Geophysical Research: Oceans, 92(C13):14251-14270. doi:10.1029/JC092iC13p14251.

Gupta, A. (2007). Large rivers; geomorphology and management. John Wiley 83 Sons. Retrieved from:https://books.google.com.au/books. Accessed 11 September, 2015.

Hall, J. W., Grey, D., Garrick, D., Fung, F., Brown, C., Dadson, S. J., and Sadoff, C. W. (2014). Coping with the curse of freshwater variability. Science, 346(6208):429-430. doi:10.1126/science.1257890.

Ham, Y.-G., Kug, J.-S., Park, J.-Y., and Jin, F.-F. (2013). Sea surface temperature in the north tropical atlantic as a trigger for el nino/southern oscillation events. Nature Geoscience, 6(2):112-116. doi:10.1038/ngeo1686. 
Henry, C., Allen, D. M., and Huang, J. (2011). Groundwater storage variability and annual recharge using well-hydrograph and GRACE satellite data. Hydrogeology Journal, 19:741755. doi:10.1007/s10040-011-0724-3.

Herrmann, S. M., Anyamba, A., and Tucker, C. J. (2005). Recent trends in vegetation dynamics in the African Sahel and their relationship to climate. Global Environmental Change, 15(4):394 - 404. doi:10.1016/j.gloenvcha.2005.08.004.

Hotelling, H. (1936). Relations between two sets of variates. Biometrika, 28(3-4):321-377. doi:: $10.2307 / 2333955$.

Hua, W., Zhou, L., Chen, H., Nicholson, S. E., Raghavendra, A., and Jiang, Y. (2016). Possible causes of the Central Equatorial African long-term drought. Environmental Research Letters, 11(12):124002. doi:10.1088/1748-9326/11/12/124002.

Janicot, S. (1992). Spatiotemporal variability of West African rainfall. part i: Regionalizations and typings. Journal of Climate, 5(5):489-497. doi:10.1175/15200442(1992)005;0489:SVOWAR $; 2.0 . C O ; 2$.

Janowiak, J. E. (1988). An investigation of interannual rainfall variability in Africa. Journal of Climate, 1(3):240-255. doi:10.1175/1520-0442(1988)001¡0240:AIOIRV ¿2.0.CO;2.

Jenkins, G. S., Adamou, G., and Fongang, S. (2002). The challenges of modeling climate variability and change in West Africa. Climatic Change, 52(3):263-286. doi:10.1023/A:1013741803144.

Jolliffe, I. T. (2002). Principal component analysis (second edition). Springer Series in Statistics. Springer, New York.

Joly, M. and Voldoire, A. (2010). Role of the Gulf of Guinea in the inter-annual variability of the West African monsoon: what do we learn from CMIP3 coupled simulations? International Journal of Climatology, 30(12):1843-1856. doi:10.1002/joc.2026.

Jung, M., Reichstein, M., Ciais, P., Seneviratne, S. I., Sheffield, J., Goulden, M. L., Bonan, G., Cescatti, A., Chen, J., Jeu, R. d., Dolman, A. J., Eugster, W., Gerten, D., Gianelle, D., Gobron, N., Heinke, J., Kimball, J., Law, B. E., Montagnani, L., Mu, Q., Mueller, B., Oleson, K., Papale, D., Richardson, A. D., Roupsard, O., Running, S., Tomelleri, E., Viovy, N., Weber, U., Williams, C., Wood, E., Zaehle, S., and Zhang, K. (2010). Recent decline in the global land evapotranspiration trend due to limited moisture supply. Nature, 467(7318):951-954.

Kasei, R., Diekkrüger, B., and Leemhuis, C. (2010). Drought frequency in the Volta Basin of West Africa. Sustainability Science, 5(1):89-97. 
Kendall, M. G. (1970). Rank correlation methods. Griffin, London, (4th edition). UK.

Koster, R. D., Dirmeyer, P. A., Guo, Z., Bonan, G., Chan, E., Cox, P., Gordon, C. T., Kanae, S., Kowalczyk, E., Lawrence, D., Liu, P., Lu, C.-H., Malyshev, S., McAvaney, B., Mitchell, K., Mocko, D., Oki, T., Oleson, K., Pitman, A., Sud, Y. C., Taylor, C. M., Verseghy, D., Vasic, R., Xue, Y., and Yamada, T. (2004). Regions of strong coupling between soil moisture and precipitation. Science, 305(5687):1138-1140. doi:10.1126/science.1100217.

Landerer, F. W. and Swenson, S. C. (2012). Accuracy of scaled GRACE terrestrial water storage estimates. Water Resources Research, 48(4):W04531. doi:10.1029/2011WR011453.

Latif, M. and Barnett, T. (1996). Decadal climate variability over the North Pacific and North America: Dynamics and predictability. Journal of Climate, 9(10):2407-2423. doi:10.1175/1520-0442(1996)009¡2407:DCVOTN¿2.0.CO;2.

Lebel, T. and Ali, A. (2009). Recent trends in the Central and Western Sahel rainfall regime (1990-2007). Journal of Hydrology, 375(12):52 - 64. doi:10.1016/j.jhydrol.2008.11.030.

Lebel, T., Delclaux, F., Le Barbé, L., and Polcher, J. (2000). From GCM scales to hydrological scales: rainfall variability in West Africa. Stochastic Environmental Research and Risk Assessment, 14(4):275-295. doi:10.1007/s004770000050.

Lee, H., Beighley, R. E., Alsdorf, D., Jung, H. C., Shum, C., Duan, J., Guo, J., Yamazaki, D., and Andreadis, K. (2011). Characterization of terrestrial water dynamics in the Congo Basin using GRACE and satellite radar altimetry. Remote Sensing of Environment, 115(12):3530 - 3538. doi:10.1016/j.rse.2011.08.015.

Lettenmaier, D. P. (2005). Observations of the global water cycle global monitoring networks. in Encyclopedia of Hydrological Sciences, 5, edited by M G Anderson.:2719-2732. John Wiley \& Sons, Ltd.

Li, J., Lewis, J., Rowland, J., Tappan, G., and Tieszen, L. (2004). Evaluation of land performance in Senegal using multi-temporal NDVI and rainfall series. Journal of Arid Environments, 59(3):463 - 480. doi:10.1016/j.jaridenv.2004.03.019.

Losada, T., Rodríguez-Fonseca, B., Janicot, S., Gervois, S., Chauvin, F., and Ruti, P. (2010). A multi-model approach to the Atlantic Equatorial mode: impact on the West African monsoon. Climate Dynamics, 35(1):29-43. doi:10.1007/s00382-009-0625-5.

Machiwal, D. and Jha, M. K. (2012). Hydrological time series: theory and practice. Springer. India.

Mann, H. B. (1945). Nonparametric tests against trend. Econometrica, 13(3):245-259. doi:10.2307/1907187. 
Mishra, V., Dominguez, F., and Lettenmaier, D. P. (2012). Urban precipitation extremes: How reliable are regional climate models? Geophysical Research Letters, 39(3):L03407. doi:10.1029/2011GL050658.

Mohino, E., Janicot, S., and Bader, J. (2011a). Sahel rainfall and decadal to multi-decadal sea surface temperature variability. Climate Dynamics, 37:419-440. doi:10.1007/s00382010-0867-2.

Mohino, E., Rodrguez-Fonseca, B., Losada, T., Gervois, S., Janicot, S., Bader, J., Ruti, P., and Chauvin, F. (2011b). Changes in the interannual SST-forced signals on West African rainfall. AGCM intercomparison. Climate Dynamics, 37(9-10):1707-1725. doi:10.1007/s00382-011-1093-2.

Moore, P. and Williams, S. D. P. (2014). Integration of altimetry lake lavels and GRACE gravimetry over Africa: Inferences for terrestrial water storage change 2003-2011. Water Resources Research, 50:9696-9720. doi:10.1002/2014WR015506.

Ndehedehe, C., Awange, J., Agutu, N., Kuhn, M., and Heck, B. (2016a). Understanding changes in terrestrial water storage over West Africa between 2002 and 2014. Advances in Water Resources, 88:211-230. doi:10.1016/j.advwatres.2015.12.009.

Ndehedehe, C. E., Agutu, N. O., Okwuashi, O. H., and Ferreira, V. G. (2016b). Spatio-temporal variability of droughts and terrestrial water storage over Lake Chad Basin using independent component analysis. Journal of Hydrology, 540:106- 128. doi:10.1016/j.jhydrol.2016.05.068.

Ndehedehe, C. E., Awange, J., Kuhn, M., Agutu, N., and Fukuda, Y. (2017a). Analysis of hydrological variability over the Volta river basin using in-situ data and satellite observations. Journal of Hydrology: Regional studies, 12:88-110. doi:10.1016/j.ejrh.2017.04.005.

Ndehedehe, C. E., Awange, J., Kuhn, M., Agutu, N., and Fukuda, Y. (2017b). Climate teleconnections influence on West Africa's terrestrial water storage. Hydrological Processes, 31(18):3206-3224. doi: 10.1002/hyp.11237.

Ndehedehe, C. E., Awange, J. L., Corner, R., Kuhn, M., and Okwuashi, O. (2016c). On the potentials of multiple climate variables in assessing the spatio-temporal characteristics of hydrological droughts over the Volta Basin. Science of the Total Environment, 557558:819-837. doi:10.1016/j.scitotenv.2016.03.004.

Ngom, F., Tweed, S., Bader, J.-C., Saos, J.-L., Malou, R., Leduc, C., and Leblanc, M. (2016). Rapid evolution of water resources in the Senegal delta. Global and Planetary Change, 144:34 - 47. doi:10.1016/j.gloplacha.2016.07.002. 
Nicholson, S. (2005). On the question of the recovery of the rains in the West African Sahel. Journal of Arid Environments, 63(3):615-641. doi:10.1016/j.jaridenv.2005.03.004.

Nicholson, S. (2013). The West African Sahel: a review of recent studies on the rainfall regime and its interannual variability. ISRN Meteorology, 2013(453521):1-32. doi:10.1155/2013/453521.

Nicholson, S. and Selato, J. (2000). The influence of La-Nina on African rainfall. International Journal of Climatology, 20(14):1761-1776. doi:10.1002/10970088(20001130)20:14¡1761::AID-JOC580¿3.0.CO;2-W.

Nicholson, S. E. (2008). The intensity, location and structure of the tropical rainbelt over West Africa as factors in interannual variability. International Journal Of Climatology, 28:17751785. doi:10.1002/joc.1507.

Nicholson, S. E. and Palao, I. M. (1993). A re-evaluation of rainfall variability in the Sahel. part i. characteristics of rainfall fluctuations. International Journal of Climatology, 13(4):371-389. doi:10.1002/joc.3370130403.

Nicholson, S. E., Some, B., and Kone, B. (2000). An analysis of recent rainfall conditions in West Africa, including the rainy seasons of the $1997 \mathrm{El}$ Nin̈o and the 1998 La Nia years. Journal of Climate, 13(14):2628-2640. doi:10.1175/15200442(2000)013;2628:AAORRC ¿2.0.CO;2.

Nicholson, S. E. and Webster, P. J. (2007). A physical basis for the interannual variability of rainfall in the Sahel. Quarterly Journal Of The Royal Meteorological Society, 133(629):2065-2084. doi:10.1002/qj.104.

Nka, B. N., Oudin, L., Karambiri, H., Paturel, J. E., and Ribstein, P. (2015). Trends in floods in West Africa: analysis based on 11 catchments in the region. Hydrology and Earth System Sciences, 19(11):4707-4719. doi:10.5194/hess-19-4707-2015.

Odekunle, T. O. and Eludoyin, A. O. (2008). Sea surface temperature patterns in the Gulf of Guinea: their implications for the spatio-temporal variability of precipitation in West Africa. International Journal Of Climatology, 28:15071517. doi:10.1002/joc.1656.

Oettli, P., Sultan, B., Baron, C., and Vrac, M. (2011). Are regional climate models relevant for crop yield prediction in West Africa? Environmental Research Letters, 6(1):014008. doi:10.1088/1748-9326/6/1/014008.

Olsson, L., Eklundh, L., and Ard, J. (2005). A recent greening of the Saheltrends, patterns and potential causes. Journal of Arid Environments, 63(3):556 - 566. doi:0.1016/j.jaridenv.2005.03.008. 
Otto, F. E. L., Jones, R. G., Halladay, K., and Allen, M. R. (2013). Attribution of changes in precipitation patterns in african rainforests. Philosophical Transactions of the Royal Society of London B: Biological Sciences, 368(1625). doi:10.1098/rstb.2012.0299.

Paeth, H., Fink, A., Pohle, S., Keis, F., Machel, H., and Samimi, C. (2012). Meteorological characteristics and potential causes of the 2007 flood in sub-Saharan Africa. International Journal of Climatology, 31:1908-1926. doi:10.1002/Joc.2199.

Paolino, D. A., III, J. L. K., Kirtman, B. P., Min, D., and Straus, D. M. (2012). The impact of land surface and atmospheric initialization on seasonal forecasts with ccsm. Journal of Climate, 25(3):1007-1021. doi:10.1175/2011JCLI3934.1.

Petropoulos, G. P., Ireland, G., and Barrett, B. (2015). Surface soil moisture retrievals from remote sensing: Current status, products, and future trends. Physics and Chemistry of the Earth, Parts $A / B / C, 83-84: 36$ - 56. doi:10.1016/j.pce.2015.02.009.

Phillips, T., Nerem, R. S., Fox-Kemper, B., Famiglietti, J. S., and Rajagopalan, B. (2012). The influence of ENSO on global terrestrial water storage using GRACE. Geophysical Research Letters, 39:L16705. doi:10.1029/2012GL052495, 2012.

Preisendorfer, R. (1988). Principal component analysis in meteorology and oceanography. Developments in Atmospheric Science 17. Elsevier, Amsterdam.

Prudhomme, C., Giuntoli, I., Robinson, E. L., Clark, D. B., Arnell, N. W., Dankers, R., Fekete, B. M., Franssen, W., Gerten, D., Gosling, S. N., Hagemann, S., Hannah, D. M., Kim, H., Masaki, Y., Satoh, Y., Stacke, T., Wada, Y., and Wisser, D. (2014). Hydrological droughts in the 21st century, hotspots and uncertainties from a global multimodel ensemble experiment. Proceedings of the National Academy of Sciences, 111(9):3262-3267. doi:10.1073/pnas.1222473110.

Rangelova, E., van der Wal, W., Braun, A., Sideris, M. G., and Wu, P. (2007). Analysis of Gravity Recovery and Climate Experiment time-variable mass redistribution signals over North America by means of principal component analysis. Journal of Geophysical Research: Earth Surface, 112(F3):2156-2202. doi:10.1029/2006JF000615.

Redelsperger, J.-L. and Lebel, T. (2009). Surface processes and water cycle in West Africa, studied from the AMMA-CATCH observing system. Journal of Hydrology, 375(1-2):1-2. doi:10.1016/j.jhydrol.2009.08.017.

Reichle, R. H., Koster, R. D., Lannoy, G. J. M. D., Forman, B. A., Liu, Q., Mahanama, S. P. P., and Tour, A. (2011). Assessment and enhancement of MERRA land surface hydrology estimates. Journal of Climate, 24(24):6322-6338. doi:10.1175/JCLI-D-10-05033.1. 
Repelli, C. A. and Nobre, P. (2004). Statistical prediction of sea-surface temperature over the tropical Atlantic. International Journal of Climatology, 24(1):45-55. doi:10.1002/joc.982.

Reynolds, R. W., Rayne, N. A., Smith, T. M., Stokes, D. C., and Wang, W. (2002). An improved in situ and satellite SST analysis for climate. Journal of Climate, 15(3):16091625. doi:10.1175/1520-0442(2002)0153C1609:AIISAS3E2.0.CO;2.

Rienecker, M. M., Suarez, M. J., Gelaro, R., Todling, R., Bacmeister, J., Liu, E., Bosilovich, M. G., Schubert, S. D., Takacs, L., Kim, G.-K., Bloom, S., Chen, J., Collins, D., Conaty, A., da Silva, A., Gu, W., Joiner, J., Koster, R. D., Lucchesi, R., Molod, A., Owens, T., Pawson, S., Pegion, P., Redder, C. R., Reichle, R., Robertson, F. R., Ruddick, A. G., Sienkiewicz, M., and Woollen, J. (2011). MERRA: NASA's modern-era retrospective analysis for research and applications. Journal of Climate, 24(14):3624-3648. doi:10.1175/JCLI-D-1100015.1.

Robock, A., Vinnikov, K. Y., Srinivasan, G., Entin, J. K., Hollinger, S. E., Speranskaya, N. A., Liu, S., and Namkhai, A. (2000). The global soil moisture data bank. Bulletin of the American Meteorological Society, 81(6):1281-1299. doi:10.1175/15200477(2000)081¡1281:TGSMDB¿2.3.CO;2.

Rodell, M., Houser, P. R., Jambor, U., Gottschalck, J., Mitchell, K., Meng, K., Arsenault, C. J., Cosgrove, B., Radakovich, J., Bosilovich, M., Entin, J. K., Walker, J. P., Lohmann, D., and Toll, D. (2004). The global land data assimilation system. Bulletin of American Meteorological Society, 85(3):381-394. doi:10.1175/BAMS-85-3-381.R.

Sanogo, S., Fink, A. H., Omotosho, J. A., Ba, A., Redl, R., and Ermert, V. (2015). Spatiotemporal characteristics of the recent rainfall recovery in West Africa. International Journal of Climatology, 35(15):4589-4605. doi:10.1002/joc.4309.

Schewe, J., Heinke, J., Gerten, D., Haddeland, I., Arnell, N. W., Clark, D. B., Dankers, R., Eisner, S., Fekete, B. M., Colón-Gonzlez, F. J., Gosling, S. N., Kim, H., Liu, X., Masaki, Y., Portmann, F. T., Satoh, Y., Stacke, T., Tang, Q., Wada, Y., Wisser, D., Albrecht, T., Frieler, K., Piontek, F., Warszawski, L., and Kabat, P. (2013). Multimodel assessment of water scarcity under climate change. PNAS, 111(9):3245-3250, doi:10.1073/pnas.1222460110.

Schneider, U., Becker, A., Finger, P., Meyer-Christoffer, A., Ziese, M., and Rudolf, B. (2014). GPCC's new land surface precipitation climatology based on quality-controlled in situ data and its role in quantifying the global water cycle. Theoretical and Applied Climatology, 115(1-2):15-40. doi:10.1007/s00704-013-0860-x. 
Schuol, J. and Abbaspour, K. C. (2006). Calibration and uncertainty issues of a hydrological model (SWAT) applied to West Africa. Advances in Geosciences, 9:137-143. doi:advgeosci.net/9/137/2006/.

Séguis, L., Cappelaere, B., Milsi, G., Peugeot, C., Massuel, S., and Favreau, G. (2004). Simulated impacts of climate change and land-clearing on runoff from a small Sahelian catchment. Hydrological Processes, 18(17):3401-3413. doi:10.1002/hyp.1503.

Semazzi, F. H. M., Mehta, V., and Sud, Y. (1988). An investigation of the relationship between subSaharan rainfall and global sea surface temperatures. Atmosphere-Ocean, 26(1):118-138. doi:10.1080/07055900.1988.9649293.

Sen, P. K. (1968). Estimates of the regression coefficient based on Kendall's Tau. Journal of the American Statistical Association, 63(324):1379-1389. doi:10.1080/01621459.1968.10480934.

Shabbar, A. and Barnston, A. G. (1996). Skill of seasonal climate forecasts in Canada using canonical correlation analysis. Monthly Weather Review, 124(10):2370-2385. doi:10.1175/1520-0493(1996)124¡2370:SOSCFI¿2.0.CO;2.

Shahin, M. (2008). Hydrology and water resources of Africa. Water Science and Technology Library, (41). Kluwer Academic Publishers, Dordrecht, The Netherlands.

Sheffield, J. and Wood, E. F. (2008). Global trends and variability in soil moisture and drought characteristics, 1950-2000, from observation-driven simulations of the terrestrial hydrologic cycle. Journal of Climate, 21(3):432-458. doi:10.1175/2007JCLI1822.1.

Shiferaw, B., Tesfaye, K., Kassie, M., Abate, T., Prasanna, B., and Menkir, A. (2014). Managing vulnerability to drought and enhancing livelihood resilience in sub-Saharan Africa:technological, institutional and policy options. Weather and Climate Extremes, 3(0):67 - 79. doi:10.1016/j.wace.2014.04.004.

Singh, A., Kulkarni, M. A., Mohanty, U. C., Kar, S. C., Robertson, A. W., and Mishra, G. (2012a). Prediction of Indian summer monsoon rainfall (ISMR) using canonical correlation analysis of global circulation model products. Meteorological Applications, 19(2):179-188. doi:10.1002/met.1333.

Singh, A., Seitz, F., and Schwatke, C. (2012b). Inter-annual water storage changes in the Aral Sea from multi-mission satellite altimetry, optical remote sensing, and GRACE satellite gravimetry. Remote Sensing of Environment, 123:187 - 195.

Tall, M., Sylla, M. B., Diallo, I., Pal, J. S., Faye, A., Mbaye, M. L., and Gaye, A. T. (2016). Projected impact of climate change in the hydroclimatology of Senegal with a focus over 
the Lake of Guiers for the twenty-first century. Theoretical and Applied Climatology, pages 1-11. doi:10.1007/s00704-016-1805-y.

Tapley, B., Bettadpur, S., Watkins, M., and Reigber, C. (2004). The Gravity Recovery and Climate Experiment: Mission overview and early results. Geophysical Research Letters, 31:1-4. doi:10.1029/ 2004GL019920.

Thiemig, V., Rojas, R., Zambrano-Bigiarini, M., and Roo, A. D. (2013). Hydrological evaluation of satellite-based rainfall estimates over the Volta and Baro-Akobo Basin. Journal of Hydrology, 499:324 - 338. doi:10.1016/j.jhydrol.2013.07.012.

Todd, M. C. and Washington, R. (2004). Climate variability in central equatorial Africa: Influence from the Atlantic sector. Geophysical Research Letters, 31(23):L23202. doi:10.1029/2004GL020975.

Trenberth, K. E. (1997). The definition of El Niño. Bulletin of the American Meteorological Society, 78(12):2771-2777.

Unnikrishnan, P. and Jothiprakash, V. (2015). Extraction of nonlinear rainfall trends using singular spectrum analysis. Journal of Hydrologic Engineering, 20(12):1-14. doi:10.1061/(ASCE)HE.1943-5584.0001237.

Wahr, J., Molenaar, M., and Bryan, F. (1998). Time variability of the Earth's gravity field: Hydrological and oceanic effects and their possible detection using GRACE. Journal of Geophysical Research-Solid Earth, 103(B12):30205-30229. doi:10.1029/98jb02844.

Washington, R., James, R., Pearce, H., Pokam, W. M., and Moufouma-Okia, W. (2013). Congo Basin rainfall climatology: can we believe the climate models? Philosophical Transactions of the Royal Society of London B: Biological Sciences, 368(1625). doi:10.1098/rstb.2012.0296.

Werth, S., White, D., and Bliss, D. W. (2017). GRACE detected rise of groundwater in the Sahelian Niger River Basin. Journal of Geophysical Research: Solid Earth, page 2017JB014845. doi:10.1002/2017JB014845.

Wilks, D. (2011). Statistical methods in the atmospheric sciences. Academic press, (3rd Edition). USA.

Wu, M.-L. C., Reale, O., and Schubert, S. D. (2013). A characterization of Africaneasterly waves on 2.5 - 6-day and 6-9-day time scales. Journal of Climate, 26(18):6750-6774. doi:10.1175/JCLI-D-12-00336.1.

Yu, Z.-P., Chu, P.-S., and Schroeder, T. (1997). Predictive skills of seasonal to annual rainfall variations in the U.S. affiliated pacific islands: Canonical correlation analysis and 
multivariate principal component regression approaches. Journal of Climate, 10(10):25862599. doi:10.1175/1520-0442(1997)010¡2586:PSOSTA ¿2.0.CO;2.

Zhang, Q., Xu, C.-Y., Becker, S., Zhang, Z. X., Chen, Y. D., and Coulibaly, M. (2009). Trends and abrupt changes of precipitation maxima in the pearl river basin, china. Atmospheric Science Letters, 10(2):132-144. doi:10.1002/asl.221.

Zhou, L., Tian, Y., Myneni, R. B., Ciais, P., Saatchi, S., Liu, Y. Y., Piao, S., Chen, H., Vermote, E. F., Song, C., and Hwang, T. (2014). Widespread decline of congo rainforest greenness in the past decade. Nature, 509(7498):86-90. doi:10.1038/nature13265. 